\title{
Important Insight of Hypothetical Proteins from E. faecium Strain 13-022, the Drug Targeted Virulent Big-1 Adhesins: An in-silico Approach
}

\author{
Brindangnanam Pownraj ${ }^{1, *}$ Meenatchi Ramu2 ${ }^{2}$, Ekramul Haque ${ }^{2}$ \\ ${ }^{1}$ Centre for Bioinformatics, School of Life Sciences, Pondicherry University, Puducherry, INDIA. \\ 2Department of Microbiology, School of Life Sciences, Pondicherry University, Puducherry, INDIA.
}

\begin{abstract}
Background: Enterococcus faecium is an emerging multidrug resistant opportunistic pathogen responsible for causing most of the nosocomial infections. Adhesins are the cell wall anchoring proteins implicated in the pathogenesis of enterococcal infections. The present investigation is carried out to spot the occurrence of bacterial immunoglobulin-like (lg) domain-1 or Big-1 adhesins among 204 HPs from E. faecium strain 13-022. Methods: The pathogen E. faecium chromosomal strain 13-022 was searched in the NCBI database which comprised of 2746 proteins. To filter HPs, the keyword 'hypothetical proteins' with sequence length $>100$ residues was queried. The filtered $204 \mathrm{HPs}$ were subjected to functional annotation, physico-chemical properties, virulence factors, cellular location, secondary structure prediction and protein-protein interactions (PPIs). Finally, 3D models were obtained for essential non-homologous adhesins with potential drug binding pockets. Results: Primarily functional classification of 204 HPs which are assigned to 27 different functional activities with good thermal stability $(50 \%)$, hydropathicity and virulence factors (79\%). Majority of the HPs are predicted to reside in the cytoplasm and cell membrane. $78 \mathrm{HPs}$ are predicted with high confidence. Among them, 14 are having $\beta a \beta$ motifs including two adhesins and the PPI network has 4 gene set of Mga helix-turn-helix and 2 gene set of putative adhesion
\end{abstract}

and 77 proteins are essential hypothetical proteins (EHPs). Of 77 EHPs, 65 are pathogen-specific, indeed considered as probable drug targets. In these 65 essential pathogen specific proteins, 23 targets are found to be biological targets and rest are novel targets. Among 23 targets, three are adhesins those have therapeutic applications. Conclusion: The present study predicted the occurrence of virulent drug targeted Big-1 specifically bacterial non-pilus fimbriae immunoglobulin-like (lg) domain-1among 204 HPs. Its structure, function and significance were emphasized to develop novel drugs for better treatment.

Keywords: Enterococcus faecium, Big- 1 adhesins, $\beta a \beta$ motifs and Drug targets, Protein-protein Interactions, Essential Hps.

\section{Correspondence}

Ms. Brindangnanam Pownraj

Research Scholar, Center for Bioinformatics, Pondicherry University, Kalapet, Pondicherry-605014, INDIA.

Phone: +91 9444589478

Email: astra.bioinfo15@gmail.com

DOI: 10.5530/ijpi.2021.1.7

\section{INTRODUCTION}

Enterococcus faecium is a Gram-positive Lactobacillus which belongs to the Phylum Firmicutes. It is usually present in the gastrointestinal tract of animals, soil, water, food, hospital outbreaks and surgical equipments. ${ }^{1}$ According to Gao (2018), its mode of action is found to be sporadically associated opportunistic pathogens. ${ }^{2}$ At the same time, $1 \%$ of human gut microbiota is constituted by Enterococcus thus, it is traditionally believed as a commensal bacterium. For the past five decades, E. faecium is emerging as one of the leading infectious bacterium as it is liable for most of the nosocomial infections. ${ }^{1,3}$ The Intensive Care Unit (ICUs) 2016 surveillance report states that E. faecium is responsible for common healthcare-associated infections such as urinary tract infection, bloodstream infection, pneumonia, surgical site infections and most of the antimicrobial resistant pathogens of Enterococcus species. ${ }^{4}$

Several aggregates and virulent factors are involved in pathogenicity to promote Enterococcus tenacity: adhesins are one of them. Adhesins are the first entity interacting with the host by means of colonization/ adhesions as a primary cause of infection or helps in stable surface binding. There are two types of adhesins, fimbrial and afimbrial. The classical example of bacterial adhesin structures are fimbriae or pilus. Fimbrial adhesins belong to group of pilus-specific housekeeping sortases. ${ }^{5}$ Basically, these are long polymeric structures linked covalently by single chain of protein subunits ended up with two forms (major

and minor) of adhesins liable for cell wall anchoring and pathogenicity [Figure 1]. ${ }^{6}$

Afimbrial adhesins (non-pilus) are the group of proteins lacking long polymeric fimbrial structures, that generally mediates additional close contact with the host cell which occurs over a shorter range than with
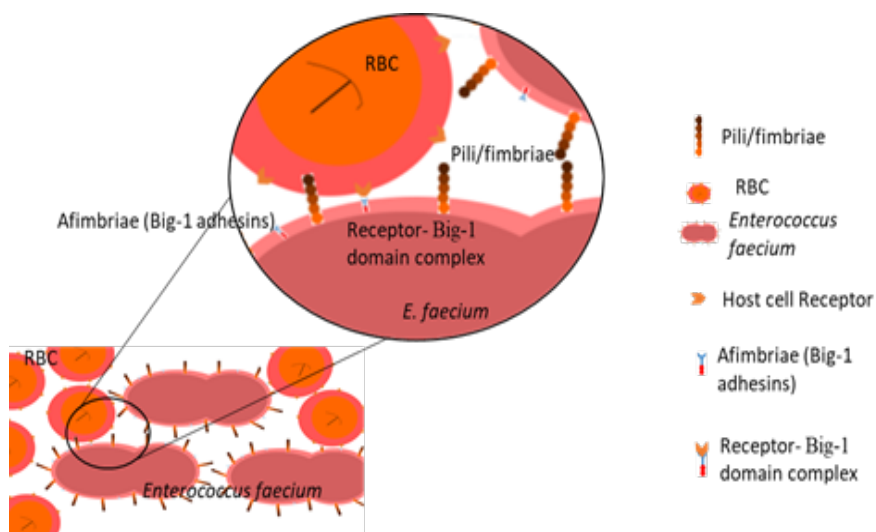

Figure 1: Afimbrial (Big-1 adhesins) adhesins interacting with host red blood cells (RBC). 
fimbriae. ${ }^{7,8}$ As a virulent factor, they play a key role in the host cell surface colonization. ${ }^{9}$ Furthermore, intra and extracellular adhesins promote clonal population of Enterococcus thus causes infections. ${ }^{10,11}$ Genetic acquisition and evolution of E. faecium are the primary reason for the multidrug resistance. ${ }^{12,13}$ This suggests the need to develop new drugs for preventing and precluding these infections.

The genes with indefinite homologous termed hypothetical or unknown/ uncharacterized because it is unclear whether they encode actual protein function. ${ }^{14-16}$ Several bioinformatics tools and soft-wares have been developed to predict the functions of unknown proteins based on the sequences. Since November $11^{\text {th }}, 2020$, the NCBI database was found to contain 2061 genome assemblies and annotation reports of E. faecium, out of which 155 are complete genome sequence data, 17 chromosomal sequences, 866 scaffold sequences and 1023 contig sequences. At chromosome level, the GC content varies between $37-40 \%$ with chromosome and plasmid replicons. Each chromosome has 2000 to 3400 proteins, out of these 240 to 780 are hypothetical proteins (HPs).

A large number of HPs from E. faecium chromosomal strain 13-022 were annotated in this study. Further, classification of HPs into different functional categories reveal the presence of virulent adhesins and their functions and structures. Studies on HPs suggests the significance of predicting the functions of unknown proteins and identification of novel drug targets for the improving the treatment methods of various nosocomial infections.

\section{MATERIALS AND METHODS}

\section{Retrieval of the hypothetical protein}

The E. faecium chromosomal strain was searched in the database of NCBI using the keyword, "Enterococcus faecium". The proteins from genome assembly and annotation report of E. faecium strain 13-022 was filtered by hitting the search for "hypothetical protein". With the retrieved HPs, the primary, secondary and tertiary analysis were performed as depicted in the Figure 2.

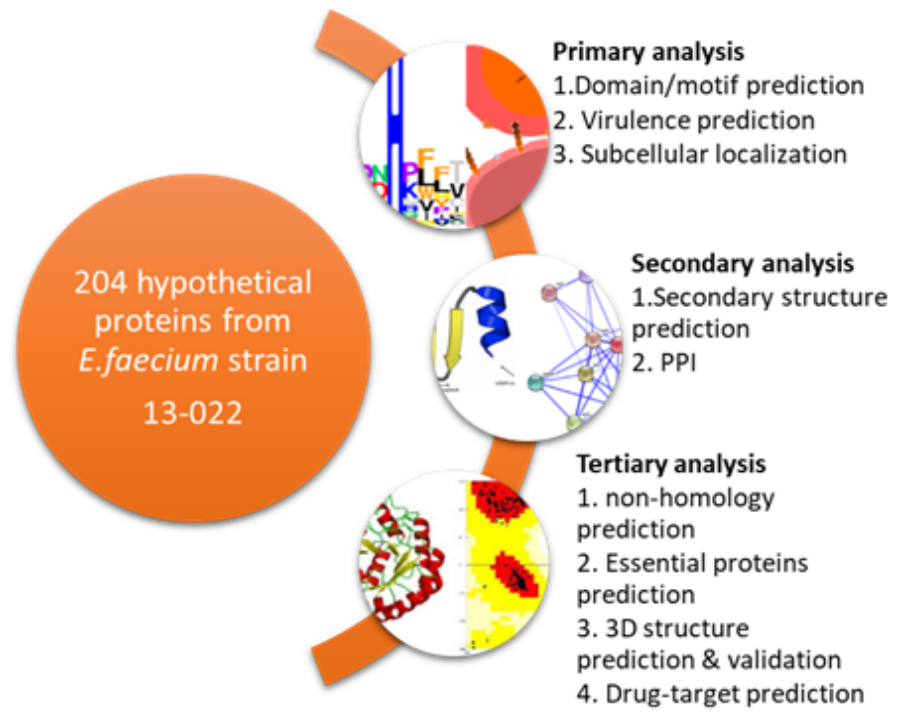

Figure 2: Complete workflow.

\section{Primary analysis}

\section{Domain/motif prediction}

The publically available bioinformatics tools and databases such as NCBI PSI-BLAST, Conserved Domain Database (CDD), Pfam and InterProScan were used to uncover the functions of HPs. Homologous proteins were predicted by searching sequences with high similarity and identity using BLAST and distantly related proteins were predicted using PSI-BLAST (based on position specific scoring matrix (PSSM)). Functional motifs/domains present in HPs were predicted using CDD, ${ }^{17}$ Pfam $^{18}$ and InterProScan. ${ }^{19}$ Sequences with high confidence were subjected to further analysis.

\section{Physicochemical properties of HPs}

The theoretical physicochemical properties of HPs were computed using ProtParam tool available at ExPASy server. The output parameters were isoelectric point (pI), molecular weight, instability index ${ }^{20}$ aliphatic index, ${ }^{21}$ and grand average hydropathy (GRAVY). ${ }^{22}$

\section{Subcellular localization prediction}

The subcellular localization of HPs was predicted by CELLO2GO and Gpos-mPLoc. CELLO2GO (http://cello.life.nctu.edu.tw/cello2go/) uses SVM (support vector machine) and BLAST-homology searching approaches to find the subcellular localization and Gene Ontology (GO). ${ }^{23}$ Gpos-mPLoc (http://www.csbio.sjtu.edu.cn/bioinf/Gpos-multi) is one of the package from Cell-PLoc 2.0 server, specific for predicting subcellular localization of gram positive bacterial proteins. ${ }^{24}$

\section{Virulence prediction of HPS}

To predict the virulent HPs, VICMpred and Virulentpred were used. VICMpred (http://crdd.osdd.net/raghava/vicmpred/) is a support vector machine (SVM) based web-application server aimed to categorize the given protein into virulence factors, information molecule, cellular process and metabolism molecule. ${ }^{25}$ The Virulentpred server (http:// bioinfo.icgeb.res.in/virulent/) uses bi-layer cascade SVM based method having domain/motif patterns to predict the bacterial virulent proteins. ${ }^{26}$

\section{Secondary analysis}

\section{Complex super-secondary structure prediction}

The core complex super secondary structure in protein is loop-helixloop ( $\beta \alpha \beta$ motifs) where functional active sites commonly occur. ${ }^{27}$ To predict the $\beta \alpha \beta$ motifs of HPs, consensus secondary structure prediction tool (https://npsa-prabi.ibcp.fr/cgi-bin/npsa_automat.pl?page=/NPSA/ npsa_seccons.html) is used. It is based on database of secondary structure assignment for all protein entries (DSSP) with significant parameters (Garnier, ${ }^{28}$ PREDATOR, ${ }^{29}$ SOPM (a Self-Optimized Method for protein secondary structure prediction) ${ }^{30}$ and SOPMA (Self-Optimized Prediction Method with Alignment) ${ }^{31}$ to predict the conformational state of each residue.

\section{Prediction of protein-protein interaction}

STRING (https://string-db.org/) database was used to predict the proteinprotein interactions (PPI). PPIs are derived from five main sources: Genomic context predictions, advanced in-silico lab experiments and coexpression, automated text mining and prior knowledge/information. ${ }^{32}$ Multiple protein sequences (HPs with high confidence) were searched by specifying the organism name 'Enterococcus faecium'. The list of matched proteins was used to construct the PPI network. 


\section{Tertiary analysis}

\section{Essential HPs and Human non-homologous prediction}

Essential genes are important for the livelihood of all domains of life. Their product comprises excellent targets for antibacterial drugs. ${ }^{33}$ To predict them the query sequences were subjected to BLAST against the Database of Essential Genes (DEG) (http://www.essentialgene.org/), which contains all the essential genes that are currently available.

To predict the human non-homologous proteins, NCBI non-redundant database queried with essential HPs with the following parameters: organism (limited): human, e-value threshold: 0.0001 and a bit score cutoff: 100. Protein sequences displayed considerable match with human proteome were excluded from further analysis. ${ }^{15,34}$

\section{Prediction of novel Drug targets}

The sieved HPs from the previous step were subjected to a homology search against the DrugBank and chEMBL (https://www.ebi.ac.uk/ chembl) database to confirm the drug gable property of the given protein. ${ }^{35}$ In contrast, the lack of hit represents the novel targets.

\section{$3 D$ structure prediction and evaluation}

The druggable targets specifically adhesins were subjected to I-TASSER sever (https://zhanglab.ccmb.med.umich.edu/I-TASSER/). It generates the sequence based 3D (3-Dimensional) models by predicting secondary structure, solvent accessibility, normalized B-factor, templates, ligand binding sites, EC-number, active sites and GO. ${ }^{36}$ Besides, structure evaluation was performed by Ramachandran plot using PROCHECK (https://servicesn.mbi.ucla.edu/PROCHECK/).

\section{RESULTS}

The term 'Enterococcus faecium' was searched in the NCBI database, which bring about 2061 genome assembly and annotation entries. Among them, enterococcus chromosomal strain 13-022 was selected which comprised of 2746 proteins. To acquire HPs, the keyword 'hypothetical proteins' was used and 503 entries were obtained. Further, HPs with sequence length $>100$ residues were filtered and retrieved and they were around 204 proteins. These filtered HPs were subjected to functional and properties prediction over series of analysis. Primary analysis provides homologous functional motif/ domain, physico-chemical properties, subcellular location and virulence factors. In secondary analysis, sequence based secondary structure depicted the potential active sites alongside PPI interactions. In tertiary analysis, 3D models were obtained for essential non-homologous adhesins with potential drug binding pockets.

The sequences of HPs were subjected to predict the motif/domain using various bioinformatics tools as mentioned in the methodology. Out of 204 HPs, 78 HPs were predicted with well-known structural domain/ motif. According to Prava (2018) and literature searches, HPs were assigned with 27 different functional activities including adhesins ${ }^{15}$ [Supplementary Table 1, Table 1 and Figure 3].

The amino acid sequences of 204 HPs were analyzed to calculate their physico-chemical properties and the result is shown in Supplementary Table 2. The molecular weight (MW) of the all predicted HPs was ranged between 10000 to $108000 \mathrm{Da}$. The intolerance of surrounding charge of the protein was predicted through isoelectric point $(\mathrm{pI})$ which ranges from 4.0 to 11.0. The thermostability of the HPs was determined by high aliphatic index value ranges from 40.0 to 162.0 . The better interaction of HPs with water disclosed by low grade average of hydropathy ranges (GRAVY) from -1.0 to 6.0. The stability of the protein was determined by the value of instability index which is <40. Out of 204 HPs, 118 HPs were stable including adhesins (WP_002286311.1 and WP_002340339) [Supplementary Table 2].

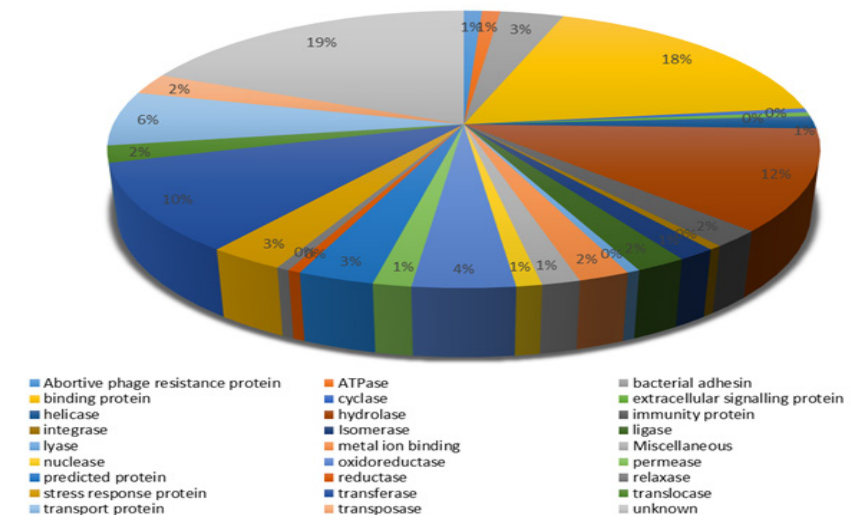

Figure 3: The functional assignment of HPs from E. faecium 13-022.

Subcellular localization analysis of HPs helps in classifying them as drug and vaccine targets. Via Gpos-mPLo, 87 membrane proteins, 56 extracellular and 61 biased proteins were localized. In a total of 5 adhesins, 4 were predicted to present in extracellular membrane and 1 in cell membrane. Using CELLO2GO, 124 soluble cytoplasmic proteins, 24 extracellular, 53 membrane proteins, 1 cell wall protein and 1 inner membrane protein were predicted with gene_codes and their functions [Supplementary Table 3]. VICMpred depicted that out of 204 HPs, $107(52.45 \%)$ are involved in cellular process, $16(7.85 \%)$ in information storage, $67(32.84 \%)$ in metabolism and $14(6.86 \%)$ act as virulence factors. From, Virulentpred, 79\% HPs were predicted to be the virulent and the remaining 21\% were non-virulent (Supplementary Table 3).

According to Sun (2016), ${ }^{27}$ the active functional sites were predicted through searching for the $\beta a \beta$ motif pattern (eeecccccchhhhhhhcccceee) in the HP's sequences through consensus secondary structure prediction tool. Among 78, $12 \mathrm{HPs}$ were having this pattern altogether two adhesin (WP_002289495.1 and WP_002345015.1) proteins (Table 1).

Using STRING database, these $78 \mathrm{HPs}$ (Table 1) were subjected to the construction of PPI network. Subsequently, 49 proteins from $E$. faecium C68 and 44 proteins from E. faecium NRRLB2354 were the two sets of output matched with the input E. faecium 13-022 HPs sequences. The E. faecium C68 was selected to construct the PPI network as of maximum hit. The network statistics displayed 57 nodes, 68 edges with $p$-value of $<1.0 \mathrm{e}-16,2.39$ average node degree and 0.43 average local clustering coefficient. The functional enrichment of the network has the following pfam domains, 2 gene set of putative adhesion domain and 4 gene set of Mga helix-turn-helix domain with the false discovery rate of 0.0089 and 0.0379 , respectively [Figure 4].

Same set of proteins (78 HPs) were subjected to search against DEG database. It showed hit for 77 HPs and considered as the essential HPs (EHPs). These 77 EHPs were subjected to protein BLAST (BLASTp) search against Homo sapiens (taxid: 9606) proteome of the nonredundant database with significant parameters. Out of which, 65 proteins were exclusively present on pathogen and predicted as the potential drug targets. While excluding the significant hits, out of 5 adhesin, 2 showed similar match with human proteome (excluded from the list subsequently) and the residual were considered as novel targets.

These 65 human non-homologous HPs were taken for homology search against DrugBank/chEMBL to find the potential drug targets. Among them, 23 HPs including 3 adhesins were showed 50 to $68.6 \%$ similarity with known targets in the database (3-oxoacyl-[acyl-carrierprotein] synthase 2, 70S-ribosome, aminoglycoside acetyltransferase, botulinum neurotoxin-typeF, DNA polymerase-III-polC-type, fructose bisphosphate aldolase class-2, glutamyl endopeptidase, HTH-typeMgrA, outer membrane protein TolC, penicillin-binding protein, 


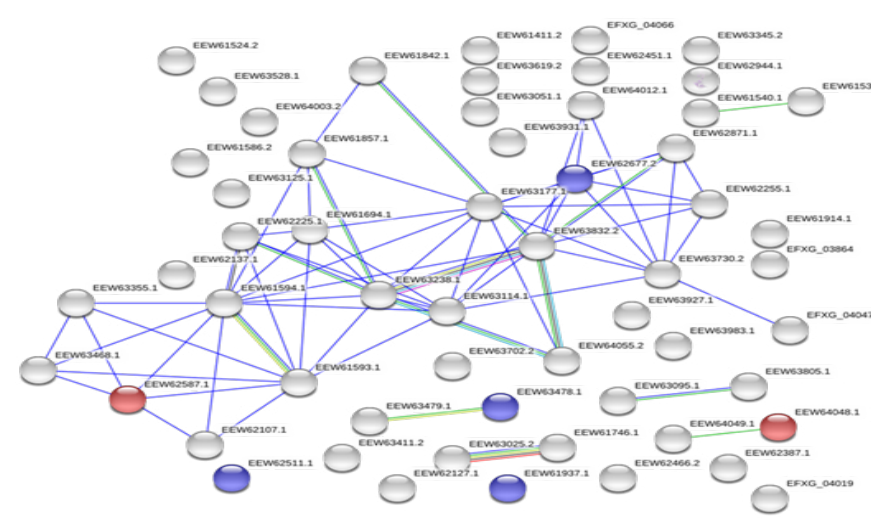

Figure 4: PPI interaction network for the $78 \mathrm{HPs}$ with high confidence showed that EEW63468.1 (LOR-superfamily), EEW63355.1 (baeRF_family6), EEW61594.1, EEW61593.1 (YycH protein) and EEW62107.1 (Halogen_Hydrol) were interacting with EEW62587.1 (putative_adhesin (gene set-1-red sphere)) at left side corner and EEW64049.1 (DUF5348) solely interacting with EEW64048.1 (Accession_no. WP_002286311.1-putative_adhesin (gene set2-red sphere)) at right side corner. EEW63678.1 (Mga-HTH superfamily-blue sphere) solely interacted with EEW63479.1 (Accession_no.WP_002287056.1; Bacterial Ig-like domain-1 (gene set-2-grey sphere)) at 6 O' clock position Same set of proteins (78 HPs) were subjected to search against DEG database. It showed hit for $77 \mathrm{HPs}$ and considered as the essential HPs (EHPs). These 77 EHPs were subjected to protein BLAST (BLASTp) search against Homo sapiens (taxid: 9606) proteome of the non-redundant database with significant parameters. Out of which, 65 proteins were exclusively present on pathogen and predicted as the potential drug targets. While excluding the significant hits, out of 5 adhesin, 2 showed similar match with human proteome (excluded from the list subsequently) and the residual were considered as novel targets.

peptide deformylase, ribokinase, sialidase-A, telomere resolvase rest, topoisomerase-IV-subunit-A, toxin-A, UDP-N-acetylmuramoylAlanine-D-glutamate-ligase). The rest of the reputed drug target candidates can be considered as novel targets, which need further experimental validation.

In a total of 23 potential drug targets, 5 are adhesins. Adhesins are one of the significant virulent factor involved in causing infection. Out of 5 adhesins, 3 (WP_002287056.1, WP_002286311.1 and WP_002340339.1) were exclusively present on the surface of the pathogen that can be targeted for therapeutic applications as penicillin binding protein4, uracil phosphoribosyl transferase and botulinum neurotoxin Type-F. Plus, 2 adhesins (WP_002287056.1 and WP_002340339.1) sequence and structures were similar to Big-1 domain adhesins. Via, I-TASSER and PROCHECK server 3D models for the three virulent adhesins were predicted and validated. The structure prediction and validation details are given in the Table 2 . The validated structures were submitted to the protein model database with the following PMDB_ID PM0082281, PM0082280 and PM0082282.

\section{DISCUSSION}

The function of HPs encoded by protein coding genes are unknown hence this study attempts to open up a path to functional characterization of these proteins. In a total of $204 \mathrm{HPs}, 190 \mathrm{HPs}$ functions were predicted by different bioinformatics tools, among them 78 were predicted with high confidence and 27 enzymatic activities including adhesins.

All HPs including adhesins predicted to contain significant thermostability, hydropathicity, MW and Isoelectric point and instability index confirms the pathogenicity of the organism. As reported for Haemophilus influenza, high molecular weight adhesins attributed to human epithelial binding. ${ }^{37}$ Similarly, adhesion (accession_ no.WP_002340339.1) has highest MW, possibly supports human

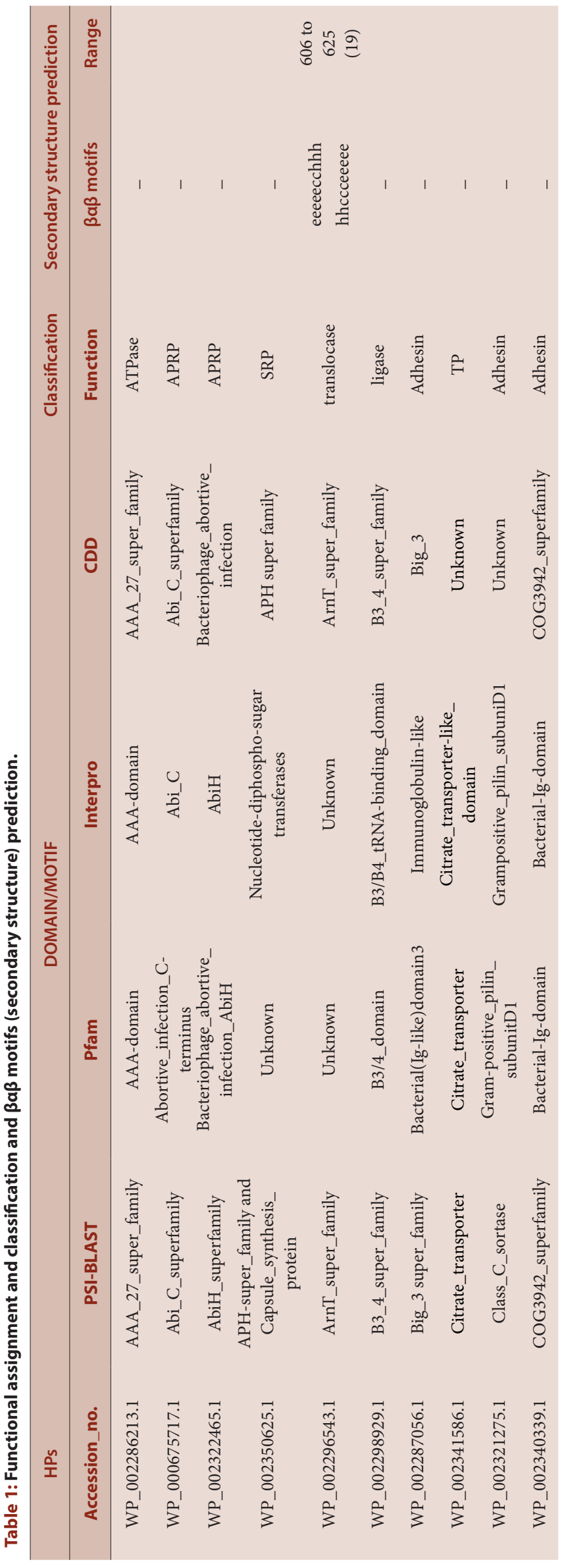




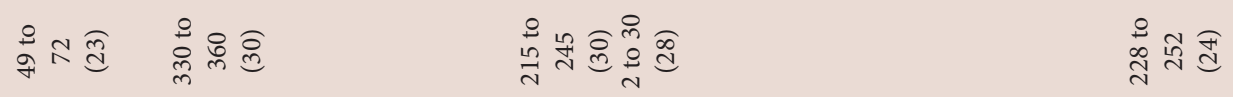

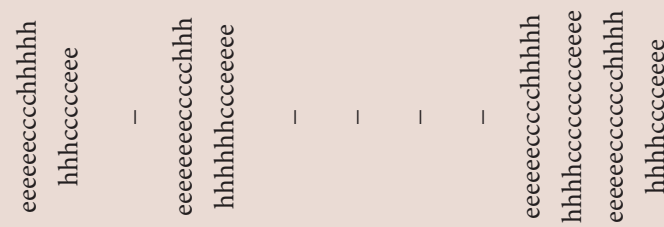

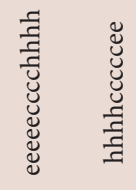

\|\|$\|\cdot\|\|\|\|\cdot\|=\|\|$

(a)

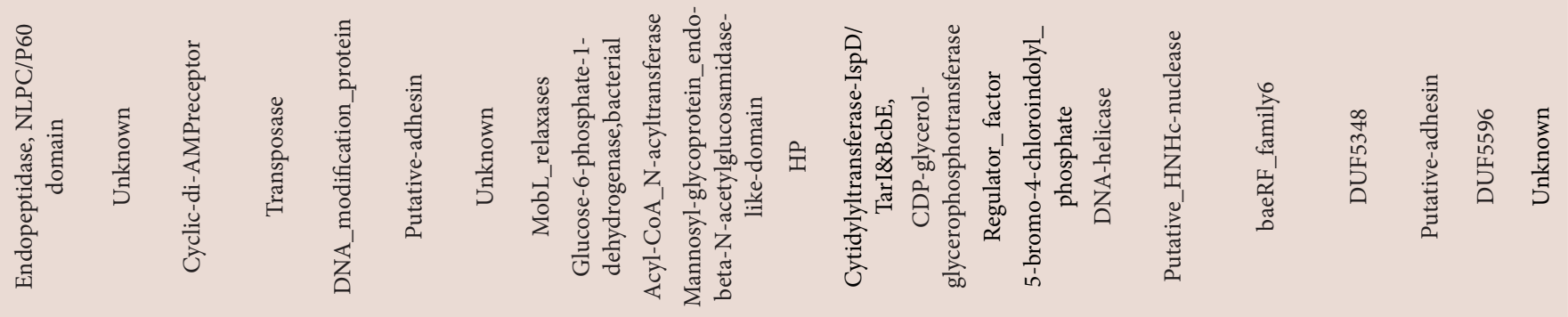

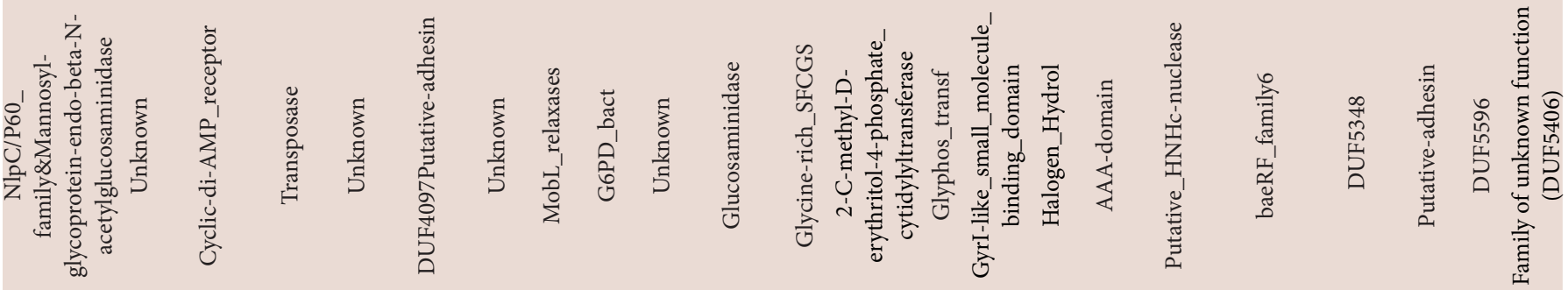

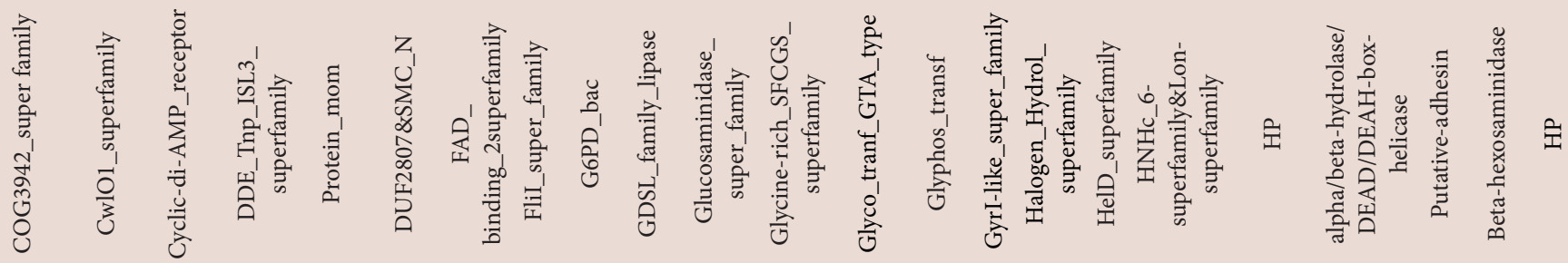

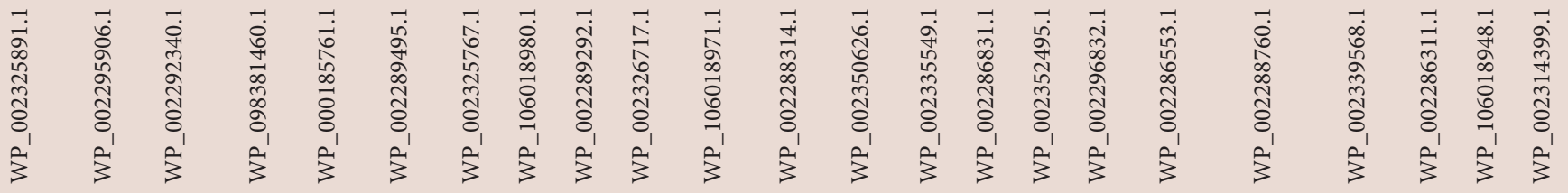




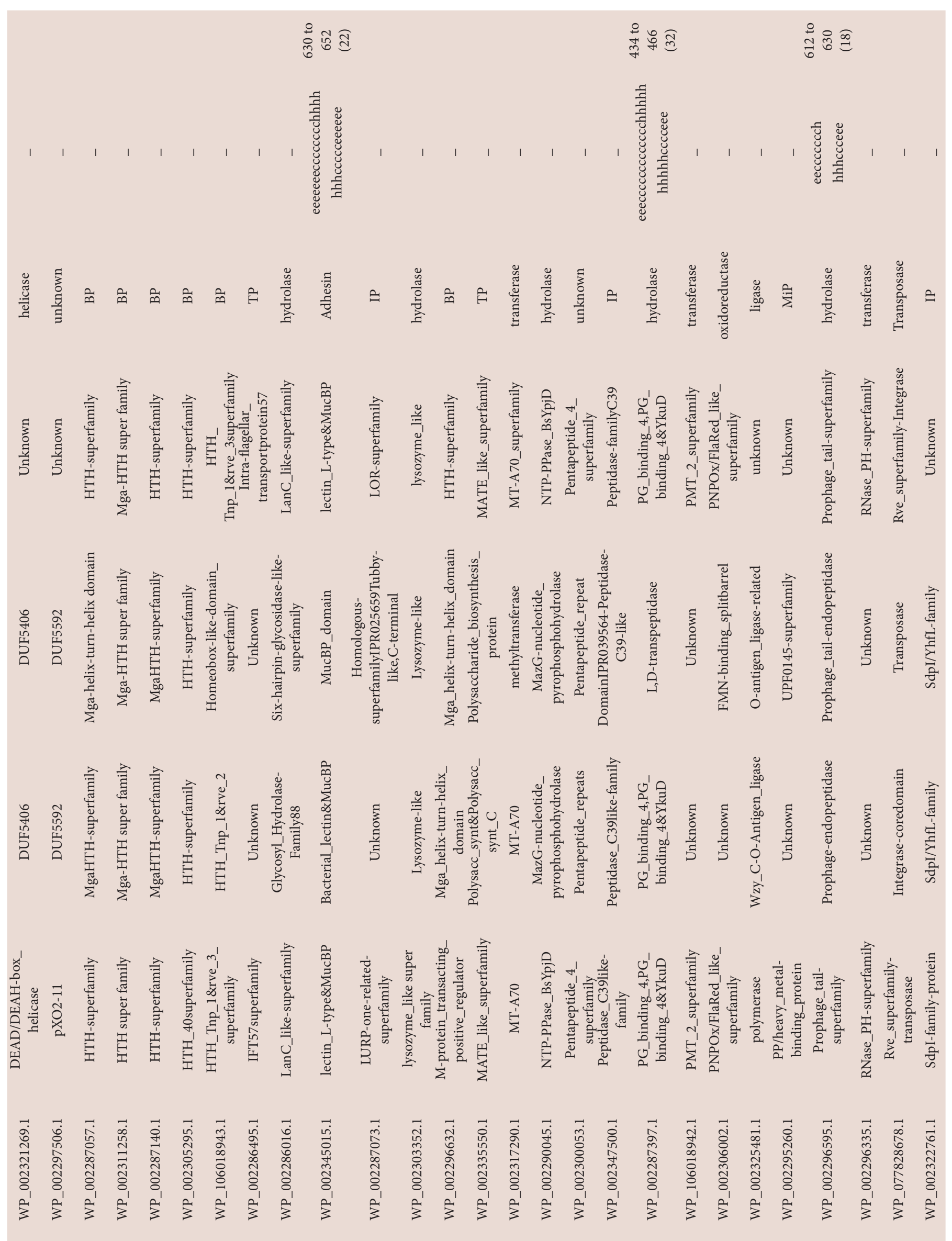




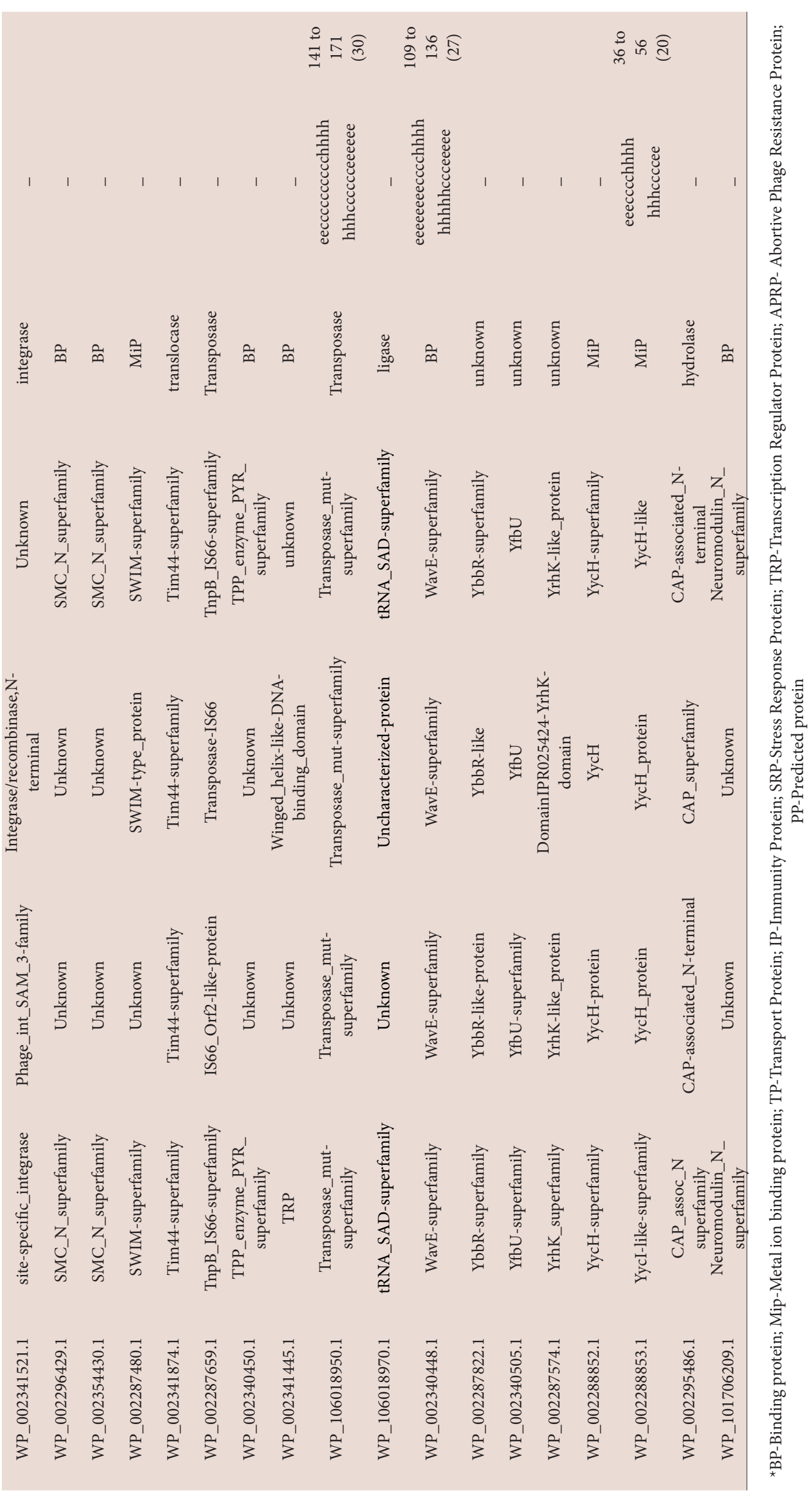


Table 2: I-TASSER Models for three virulent adhesins with structure evaluation.

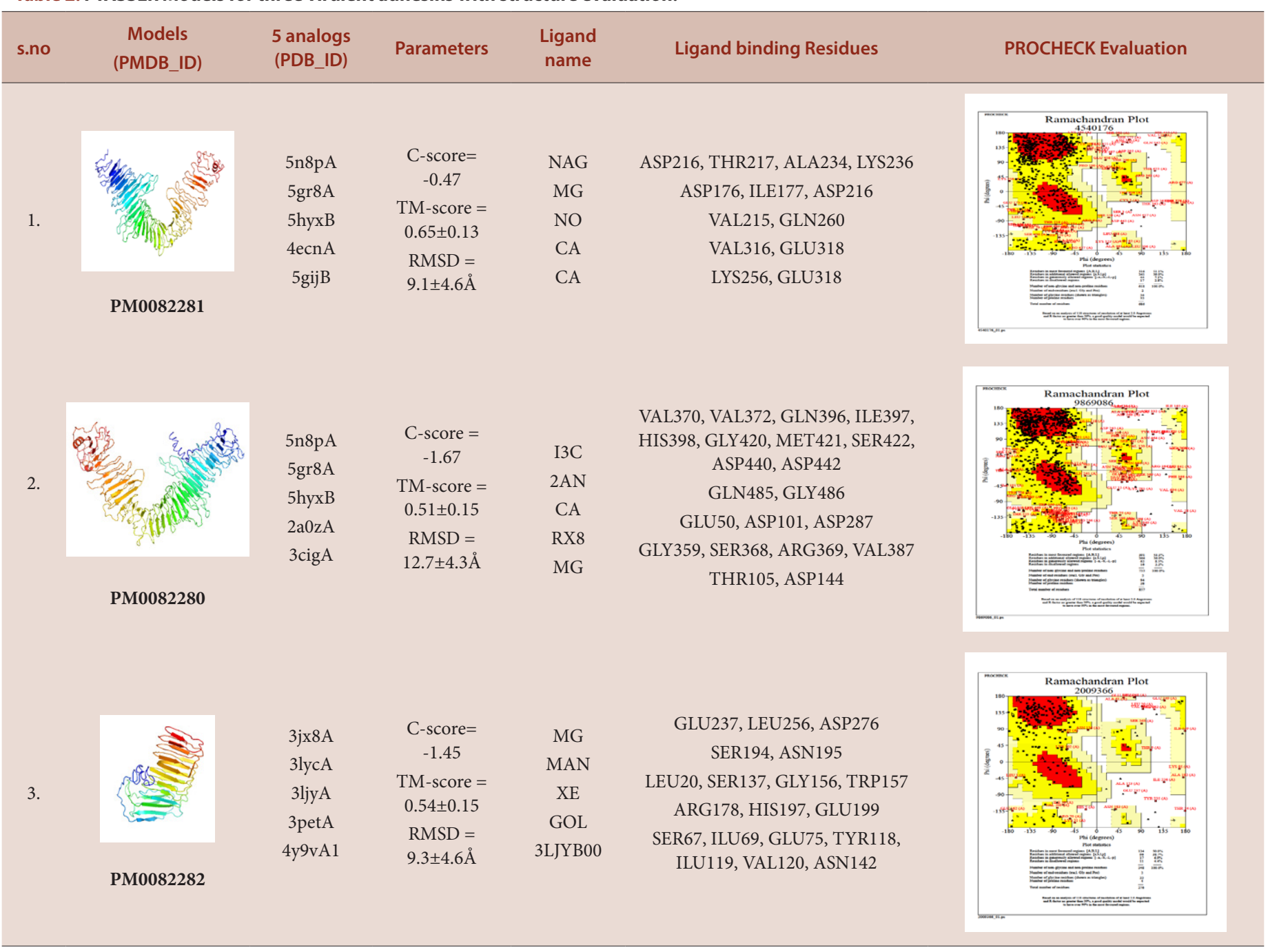

epithelial binding. Adhesin's thermostability plays a major role in the compactness of the $\beta$-barrel like IgG and it also increases the resistant against proteases. ${ }^{5}$

The virulence factors are the key to design new anti-virulent drugs to prevent the host from the infection. ${ }^{38} 79 \%$ HPs were predicted to be virulent and majority of them reside in the cytoplasm and cell membrane including seven Ig-like domain containing adhesins. According to Prava (2018), cytoplasmic proteins are probable drug target and membrane proteins are the potential vaccine target. ${ }^{15}$ The ideal fixed length for the reported $\beta a \beta$ motifs pattern was maximum up to 32 . Approximately, $8 \%$ HPs including two adhesin (WP_002289495.1 and WP_002345015.1) proteins have this pattern possibly contain active site.

According to Szklarczyk (2015), specific and productive functional relationship between two proteins, likely contributing to a common biological purpose. ${ }^{39,40}$ Likewise, the PPI network of adhesin's gene sets possibly have the common biological role [Figure 3]. Followed by PPI, essential human non-homologous and novel drug targets were predicted. Ultimately, the three therapeutic targets adhesin 3D structures were generated using I-TASSER. In general, they are beta-sheet comprising domains belongs to intimin/invasion family of bacteria, involved in initial contact with mammalian host cell through disulfide bond. And are commonly known as Big-1 domain named after found in enteropathogenic
Escherichia coli intimin and in Yersinia pseudotuberculosis invasion. ${ }^{41}$ Similarly, HP-adhesin (WP_002287056.1) is found to contain cysteine residues and subsequently belongs to intimin family. The other type of adhesins capable of forming an Ig-like topology and are belong to the group of cell surface non-fimbrial adhesins with the adhesion function even in the absence of disulfide bond. ${ }^{42}$ Correspondingly, the Ig-like domains of these adhesins (WP_002286311.1 and WP_002340339.1) possibly belong to the group of non-fimbrial or afimbrial adhesins, due to lacks disulfide bond. And all three adhesins structures were submitted to PMDB.

\section{CONCLUSION}

The comprehensive function of hypothetical proteins is important owing to immune-informatics and therapeutic science applications. The present work unveils the function of $204 \mathrm{HPs}$ from E. faecium strain 13-022. Allinclusive analysis supports the understanding of HPs characteristics. The structural analysis of predicted adhesins showed high sequence and structural similarity with Big-1 domain and annotated to predict the active drug binding site with pathogenicity. Our findings may open up the better investigation of Big-1 domain of afimbrial adhesins as well as to find prior drugs for targeting E. faecium and other biotechnological applications such as targeting biofilm formation, quorum sensing and quorum quenching. 


\section{ACKNOWLEDGEMENT}

We thank the Centre for Bioinformatics, Pondicherry University for the computational facilities to carry out this work. We also thank Mr. Pranavathiyani G (BICPU) and Mr. Karamveer (BICPU) for their valuable suggestions and support throughout this work.

\section{CONFLICT OF INTEREST}

The authors declare no conflict of interest.

\section{ABBREVIATIONS}

Big-1: Bacterial immunoglobulin-like (Ig) domain 1; CDD: Conserved Domain Database; DEG: Database of Essential Genes; DSSP: Secondary Structure assignment for all Protein entries; EHPs: Essential hypothetical proteins; GO: Gene Ontology; GRAVY: Grand average hydropathy; HPs: Hypothetical Proteins; PPI: Protein-Protein interactions; PSIBLAST: Position-Specific Iterative Basic Local Alignment Search Tool; PSSM: Position Specific Scoring Matrix; SOPM: Self-Optimized Method for protein secondary structure prediction; SOPMA: Self-Optimized Prediction Method with Alignment; SVM: Support Vector Machine.

\section{REFERENCES}

1. Dubin K, Pamer EG. Enterococci and Their Interactions with the Intestinal Microbiome. Microbiol Spectr. 2014;5(6):1-24.

2. Gao W, Howden BP, Stinear TP. Evolution of virulence in Enterococcus faecium, a hospital-adapted opportunistic pathogen. Curr Opin Microbiol. 2018;41:76-82.

3. Hancock LE, Murray BE, Sillanpää J. Enterococci: From Commensals to Leading Causes of Drug Resistant Infection. Enterococcal Cell Wall Components Struct. 2014.

4. Salmanov AG, Vdovychenko SY, Litus OI, Litus VI, Bisyuk YA, BondarenkoTM, et al. Prevalence of health care-associated infections and antimicrobial resistance of the responsible pathogens in Ukraine: Results of a multicenter study (20142016). Am J Infect Control. 2019;47(6):e15-20.

5. Vengadesan K, Narayana SVL. Structural biology of Gram-positive bacterial adhesins. Protein Science. 2011;20(5):759-72.

6. Haiko J, Westerlund-Wikström B. The role of the bacterial flagellum in adhesion and virulence. Biology. 2013;2(4):1242-67.

7. Wilson JW, Schurr MJ, LeBlanc CL, Ramamurthy R, Buchanan KL, Nickerson CA. Mechanisms of bacterial pathogenicity. Postgrad Med J. 2002;78(918):21624.

8. Berne C, Ducret A, Hardy GG, Brun YV. Adhesins Involved in Attachment to Abiotic Surfaces by Gram-Negative Bacteria. Microbiol Spectr. 2015;3(4):10. 1128/microbiolspec.MB-0018-2015.

9. Klemm P, Schembri M. Bacterial adhesins: Function and structure. International Journal of Medical Microbiology. 2000;290(1):27-35.

10. Willems RJ, Schaik WV. Transition of Enterococcus faecium from commensal organism to nosocomial pathogen. Future Microbiol. 2009;4(9):1125-35.

11. Kan A, Del VI, Rudge T, Federici F, Haseloff J. Intercellular adhesion promotes clonal mixing in growing bacterial populations. J R Soc Interface. 2018;15(146):20180406.

12. Ochoa SA, Escalona G, Cruz-Córdova A, Dávila LB, Saldaña Z, CázaresDomímguez $\mathrm{V}$, et al. Molecular analysis and distribution of multidrug-resistant Enterococcus faecium isolates belonging to clonal complex 17 in a tertiary care center in Mexico City. BMC Microbiol. 2013;13(1):291.

13. Lebreton F, Schaik WV, McGuire AM, Godfrey P, Griggs A, Mazumdar V, et al Emergence of epidemic multidrug-resistant Enterococcus faecium from animal and commensal strains. M Bio. 2013;4(4):e00534-13.

14. Sivashankari S, Shanmughavel P. Functional annotation of hypothetical proteins: A review. Bioinformation. 2006;1(8):335-8.

15. Prava JGP, Pan A. Functional assignment for essential hypothetical proteins of Staphylococcus aureus N315. Int J Biol Macromol. 2018;108:765-74.

16. DaCosta WLO, Araujo CL, De A, Dias LM, DePereira LCS, Alves JTC, et al. Functional annotation of hypothetical proteins from the Exiguobacterium antarcticum strain B7 reveals proteins involved in adaptation to extreme environments, including high arsenic resistance. PLoS One. 2018;13(6):e0198965.

17. Marchler-Bauer A, Bo Y, Han L, He J, Lanczycki CJ, Lu S, et al. CDD/SPARCLE: Functional classification of proteins via subfamily domain architectures. Nucleic Acids Res. 2017;45(D1):D200-3

18. El-Gebali S, Mistry J, Bateman A, Eddy SR, Luciani A, Potter SC, et al. The Pfam protein families database in 2019. Nucleic Acids Res. 2019;47(D1):D427-32.

19. Jones P, Binns D, Chang HY, Fraser M, Li W, McAnulla C, et al. InterProScan 5: genome-scale protein function classification. Bioinformatics. 2014;30(9):123640 .

20. Guruprasad K, Reddy B, Pandit M. Correlation between stability of a protein and its dipeptide composition: A novel approach for predicting in vivo stability of a protein from its primary sequence. Protein Engineering. 1991;4(2):155-61.

21. Ikai A. Thermostability and Aliphatic Index of Globular Proteins. Journal of Biochemistry. 1981;88(6):1895-8.

22. Kyte J, Doolittle RF. A simple method for displaying the hydropathic character of a protein. J Mol Biol. 1982;157(1):105-32.

23. Yu CS, Cheng CW, Su WC, Chang KC, Huang SW, Hwang JK, et al. CELLO2GO: A web server for protein subCELlular LOcalization prediction with functional gene ontology annotation. PLoS One. 2014;9(6):e99368.

24. Shen HB, Chou KC. Gpos-mPLoc: A top-down approach to improve the quality of predicting subcellular localization of Gram-positive bacterial proteins. Protein Pept Lett. 2009;16(12):1478-84.

25. Saha S, Raghava GPS. VICMpred: An SVM-based method for the prediction of functional proteins of Gram-negative bacteria using amino acid patterns and composition. Genomics Proteomics Bioinformatics. 2006;4(1):42-7.

26. Garg A, Gupta D. Virulent Pred: A SVM based prediction method for virulent proteins in bacterial pathogens. BMC Bioinformatics. 2008;9(1):62.

27. Sun L, Hu X, Li S, Jiang Z, Li K. Prediction of complex super-secondary structure $\beta a \beta$ motifs based on combined features. Saudi J Biol Sci. 2016;23(1):66-71.

28. Kouza M, Faraggi E, Kolinski A, Kloczkowski A. The GOR Method of Protein Secondary Structure Prediction and Its Application as a Protein Aggregation Prediction Tool. Methods Mol Biol. 2017;1484:7-24.

29. Frishman D, Argos P. Incorporation of non-local interactions in protein secondary structure prediction from the amino acid sequence. Protein Eng. 1996;9(2):13342.

30. Geourjon C, Deleage G. SOPM: A self-optimized method for protein secondary structure prediction. Protein Eng. 1994;7(2):157-64.

31. Geourjon C, Deleage G. SOPMA: Significant improvements in protein secondary structure prediction by consensus prediction from multiple alignments. Comput Appl Biosci. 1995;11(6):681-4

32. Snel B, Lehmann G, Bork P, Huynen MA. STRING: A web-server to retrieve and display the repeatedly occurring neighbourhood of a gene. Nucleic Acids Res. 2000;28(18):3442-4

33. Zhang R, Ou HY, Zhang CT. DEG: A database of essential genes. Nucleic Acids Res. 2004;32(Database issue):D271-2

34. Altschul SF, Gish W, Miller W, Myers EW, Lipman DJ. Basic local alignment search tool. J Mol Biol. 1990;215(3):403-10.

35. Gaulton A, Hersey A, Nowotka M, Bento AP, Chambers J, Mendez D, et al. The ChEMBL database in 2017. Nucleic Acids Res. 2017:45(D1):D945-54.

36. Yang J, Yan R, Roy A, Xu D, Poisson J, Zhang Y. The I-TASSER Suite: Protein structure and function prediction. Nature methods. United States. 2015:12(1):7 8

37. StGeme JWR, Falkow S, Barenkamp TJS. High-Molecular-Weight Proteins of Nontypable Haemophilus influenzae Mediate Attachment to Human Epithelial Cells. Proceedings of the National Academy of Sciences of the United States of America. 1993;90(7):2875-9.

38. Allen RC, Popat R, Diggle SP, Brown SP. Targeting virulence: Can we make evolution-proof drugs?. Nature reviews. Microbiology. England. 2014;12(1):3008.

39. Szklarczyk D, Franceschini A, Wyder S, Forslund K, Heller D, Huerta-Cepas J, et al. STRING v10: Protein-protein interaction networks, integrated over the tree of life. Nucleic Acids Res. 2015;43(D1):D447-52.

40. Vega LA, Malke H, Mclver KS. Virulence-Related Transcriptional Regulators of Streptococcus pyogenes. Oklahoma City (OK). 2016.

41. Batchelor M, Prasannan S, Daniell S, Reece S, Connerton I, Bloomberg G, et al. Structural basis for recognition of the translocated intimin receptor (Tir) by intimin from enteropathogenic Escherichia coli. EMBO J. 2000;19(11):2452-64.

42. Bodelón G, Palomino C, Fernández LÁ. Immunoglobulin domains in Escherichia coli and other enterobacteria: From pathogenesis to applications in antibody technologies. FEMS Microbiol Rev. 2013;37(2)204-50. 
Table S1: Functional assignment of HPs from E. faecium strain_13-022.

\begin{tabular}{|c|c|c|c|c|c|}
\hline Accession no. & psi-blast & pfam & interpro & CDD & $\begin{array}{l}\text { Functional } \\
\text { assignment }\end{array}$ \\
\hline WP_002296358.1 & 2-phosphosulfolactate-phosphatase & Unknown & Unknown & Unknown & hydrolase \\
\hline WP_002294410.1 & 3-dehydroquinate-synthase & unknown & unknown & unknown & lyase \\
\hline WP_002295869.1 & ABC-transporter & Unknown & Unknown & Unknown & $\mathrm{TP}$ \\
\hline WP_002350628.1 & acyltransferase & Unknown & Unknown & Unknown & transferase \\
\hline WP_002298250.1 & Alkane_1-monooxygenase & Unknown & Unknown & Unknown & oxidoreductases \\
\hline WP_002289272.1 & aminopeptidase $\mathrm{P}$ family protein & Unknown & Unknown & Unknown & hydrolase \\
\hline WP_002293828.1 & ATP-binding_cassette & Unknown & Unknown & Unknown & $\mathrm{BP}$ \\
\hline WP_074400044.1 & beta-carotene_15,15'-monooxygenase & Unknown & Unknown & Unknown & oxidoreductase \\
\hline WP_002321530.1 & Class_F_sortase & Unknown & Unknown & Unknown & Adhesin \\
\hline WP_002293655.1 & ComGG & Unknown & Unknown & Unknown & $\mathrm{BP}$ \\
\hline WP_002288325.1 & CsbD-family & Unknown & Unknown & Unknown & SRP \\
\hline WP_002302842.1 & cyclase & Unknown & Unknown & Unknown & cyclase \\
\hline WP_002289403.1 & Cytoplasmic_protein & Unknown & Unknown & Unknown & unknown \\
\hline WP_049143547.1 & Cytosine_deaminase & unknown & unknown & unknown & hydrolase \\
\hline WP_002347494.1 & Dna-mismatch-repairprotein & Unknown & Unknown & Unknown & BP \\
\hline WP_002302142.1 & DUF2975 & Unknown & Unknown & Unknown & unknown \\
\hline WP_049143544.1 & DUF3221 & Unknown & Unknown & Unknown & unknown \\
\hline WP_002317282.1 & DUF3848 & Unknown & Unknown & Unknown & unknown \\
\hline WP_002287080.1 & DUF3895 & unknown & unknown & Unknown & unknown \\
\hline WP_002303842.1 & DUF4767 & Unknown & Unknown & Unknown & unknown \\
\hline WP_002326255.1 & FtsX-like-permease & Unknown & Unknown & Unknown & permease \\
\hline WP_002289445.1 & glucosyltransferase & unknown & unknown & unknown & transferase \\
\hline WP_002286559.1 & HK97-family & Unknown & Unknown & Unknown & hydrolase \\
\hline WP_000163792.1 & Insertion_element_protein & Unknown & unknown & unknown & $\mathrm{TP}$ \\
\hline WP_002287507.1 & SirB & Unknown & Unknown & Unknown & transferase \\
\hline WP_002299230.1 & Isoprenyl_transferase & Unknown & Unknown & Unknown & transferase \\
\hline WP_002295768.1 & kinase & Unknown & Unknown & Unknown & transferase \\
\hline WP_002331275.1 & Leucine_Rich_repeat & Unknown & Unknown & Unknown & Oxidoreductase \\
\hline WP_002326259.1 & lipoprotein & Unknown & Unknown & Unknown & hydrolase \\
\hline WP_010730973.1 & L-ribulose-5-phosphate 4-epimerase & Unknown & Unknown & Unknown & Isomerase \\
\hline WP_106018974.1 & L-ribulose-5-phosphate 4-epimerase & Unknown & Unknown & Unknown & Isomerase \\
\hline WP_002296631.1 & M-protein_transacting_positive_regulator & Unknown & Unknown & Unknown & $\mathrm{BP}$ \\
\hline
\end{tabular}




\begin{tabular}{|c|c|c|c|c|c|}
\hline WP_002344946.1 & $\begin{array}{c}\text { M-protein_transacting_positive_regulatorHTH/ } \\
\text { DNA-binding_protein }\end{array}$ & unknown & unknown & unknown & $\mathrm{BP}$ \\
\hline WP_002293998.1 & $\begin{array}{c}\text { Major_facilitator_superfamily domain-containing_ } \\
\text { protein }\end{array}$ & Unknown & Unknown & Unknown & $\mathrm{TP}$ \\
\hline WP_002350622.1 & mannose-6-phosphate_isomerase & Unknown & Unknown & Unknown & Isomerase \\
\hline WP_002321568.1 & MBL_fold_kynureninase & Unknown & Unknown & Unknown & transferase \\
\hline WP_010729510.1 & MP & Unknown & Unknown & Unknown & $\mathrm{BP}$ \\
\hline WP_002294011.1 & MP & Unknown & Unknown & Unknown & $\mathrm{BP}$ \\
\hline WP_002288350.1 & MP & Unknown & Unknown & Unknown & BP \\
\hline WP_002287053.1 & MP & Unknown & Unknown & Unknown & BP \\
\hline WP_002317291.1 & MP & Unknown & Unknown & Unknown & BP \\
\hline WP_002322202.1 & MP & unknown & unknown & unknown & $\mathrm{BP}$ \\
\hline WP_002296481.1 & methyltransferase & Unknown & Unknown & Unknown & transferase \\
\hline WP_002287147.1 & YtxH_domain-containing_protein & Unknown & Unknown & Unknown & Miscellaneous \\
\hline WP_106018969.1 & myosin-11-like & Unknown & Unknown & Unknown & unknown \\
\hline WP_002302096.1 & Oligosaccharide_biosynthesis_protein-Alg14 & Unknown & Unknown & Unknown & transferase \\
\hline WP_002368120.1 & PcfX-family & Unknown & Unknown & Unknown & miscellaneous \\
\hline WP_002289550.1 & penicillin-BP & Unknown & Unknown & Unknown & $\mathrm{BP}$ \\
\hline WP_002323868.1 & Peptidase_S8/XRE family & Unknown & Unknown & Unknown & hydrolase \\
\hline WP_002286523.1 & phage_gp6-like_head-tail_connector_protein & Unknown & Unknown & Unknown & hydrolase \\
\hline WP_002303420.1 & Phage-head-tail_adapter_protein & Unknown & $\begin{array}{l}\text { Putative_- } \\
\text { metalloenzymes }\end{array}$ & Unknown & hydrolase \\
\hline WP_002286524.1 & Phage_protein & Unknown & Unknown & Unknown & hydrolase \\
\hline WP_002286512.1 & Phage_tail_protein & Unknown & Unknown & Unknown & hydrolase \\
\hline WP_002295913.1 & Phage_tail_protein & Unknown & Unknown & Unknown & hydrolase \\
\hline WP_002326819.1 & PP & Unknown & Unknown & Unknown & PP \\
\hline WP_002350624.1 & PP & unknown & unknown & unknown & $\mathrm{PP}$ \\
\hline WP_002299301.1 & PP & unknown & unknown & unknown & PP \\
\hline WP_002295864.1 & PP & Unknown & Unknown & Unknown & PP \\
\hline WP_002289257.1 & PP/Glycoside hydrolase family 13 protein & Unknown & Unknown & Unknown & $\mathrm{PP}$ \\
\hline WP_010730971.1 & PP-DNA_mismatch_repair-ATPase & unknown & unknown & unknown & PP \\
\hline WP_000248477.1 & phosphatase & Unknown & Unknown & Unknown & hydrolase \\
\hline WP_002321681.1 & PutativeE3-ubiquitin-protein_ligase & Unknown & Unknown & Unknown & ligase \\
\hline WP_002324247.1 & $\begin{array}{c}\text { prepilin-type-N-terminal-cleavage/methylation } \\
\text { domain }\end{array}$ & Unknown & Unknown & Unknown & $\mathrm{TP}$ \\
\hline WP_002289649.1 & Putative-lipoprotein & Unknown & Unknown & Unknown & permease \\
\hline WP_002295447.1 & Putative-MP & Unknown & Unknown & Unknown & $\mathrm{TP}$ \\
\hline WP_002321168.1 & Putative-MP & Unknown & Unknown & Unknown & $\mathrm{TP}$ \\
\hline WP_002340550.1 & Putative-MP & unknown & unknown & unknown & $\mathrm{TP}$ \\
\hline WP_002296549.1 & Putative-MP & unknown & unknown & unknown & $\mathrm{TP}$ \\
\hline WP_002303114.1 & Putative-UV-damage_repair_protein & Unknown & Unknown & Unknown & transferase \\
\hline WP_002347528.1 & Putative-UV-damage_repair_protein & Unknown & Unknown & Unknown & transferase \\
\hline WP_002350357.1 & pXO2-10-like-protein & Unknown & Unknown & Unknown & Miscellaneous \\
\hline WP_070828461.1 & Restriction-endonuclease_subunitR & Unknown & Unknown & Unknown & $\mathrm{BP}$ \\
\hline WP_002288643.1 & ribosomal-protein-alanine- $\mathrm{N}$-acetyltransferase & Unknown & Unknown & Unknown & oxidoreductase \\
\hline WP_002301068.1 & RnfC_N-superfamily & Unknown & Unknown & $\begin{array}{l}\text { RnfC_N- } \\
\text { superfamily }\end{array}$ & oxidoreductase \\
\hline WP_002286049.1 & rRNA_processing-protein & Unknown & Unknown & Unknown & transferase \\
\hline
\end{tabular}




\begin{tabular}{|c|c|c|c|c|c|}
\hline WP_002330700.1 & $\begin{array}{l}\text { S-adenosyl-L-methionine-dependent- } \\
\text { methyltransferase }\end{array}$ & Unknown & Unknown & Unknown & transferase \\
\hline WP_002323892.1 & SdpI-family-protein & Unknown & Unknown & Unknown & IP \\
\hline WP_000455809.1 & SEC-C_domain-containing_protein & Unknown & Unknown & Unknown & $\mathrm{BP}$ \\
\hline WP_002287075.1 & Sex-pheromone_cAM373 & Unknown & Unknown & Unknown & unknown \\
\hline WP_002346986.1 & Signal-peptide & Unknown & Unknown & Unknown & translocase \\
\hline WP_074400136.1 & SIR2-family_protein/beta- $\mathrm{N}$-acetylhexosaminidase & Unknown & Unknown & Unknown & unknown \\
\hline WP_002285960.1 & Sugar-transporter & Unknown & Unknown & Unknown & unknown \\
\hline WP_106018965.1 & Terminase_large-subunit & Unknown & Unknown & Unknown & unknown \\
\hline WP_049143545.1 & TetR/AcrR-family & Unknown & Unknown & Unknown & hydrolase \\
\hline WP_002320994.1 & Tetraacyldisaccharide-4'-kinase & Unknown & Unknown & Unknown & unknown \\
\hline WP_002323140.1 & Tetratricopeptide-repeat & Unknown & Unknown & Unknown & unknown \\
\hline WP_010706480.1 & TlpA-family-disulfide-reductase & Unknown & Unknown & Unknown & reductase \\
\hline WP_002347493.1 & TPR_MLP1_2-superfamily & unknown & unknown & $\begin{array}{l}\text { TPR_MLP1_2- } \\
\text { superfamily }\end{array}$ & $\mathrm{BP}$ \\
\hline WP_002310954.1 & TraE1-conjugal_transfer-protein & Unknown & Unknown & Unknown & transferase \\
\hline WP_002304624.1 & TRP & Unknown & Unknown & Unknown & BP \\
\hline WP_074400096.1 & TRP & Unknown & Unknown & Unknown & BP \\
\hline WP_002350689.1 & transposase & unknown & unknown & unknown & transposase \\
\hline WP_002301170.1 & Trichoplein-keratin-filament-BP & Unknown & Unknown & Unknown & BP \\
\hline WP_002289192.1 & translocase-TatC & Unknown & Unknown & Unknown & translocase \\
\hline WP_002302159.1 & permease/ATPase & Unknown & Unknown & Unknown & permease \\
\hline WP_002320976.1 & V-type-ATPase & Unknown & Unknown & Unknown & ATPase \\
\hline WP_002340448.1 & WavE-superfamily & $\begin{array}{l}\text { WavE- } \\
\text { superfamily }\end{array}$ & $\begin{array}{l}\text { WavE- } \\
\text { superfamily }\end{array}$ & $\begin{array}{l}\text { WavE- } \\
\text { superfamily }\end{array}$ & $\mathrm{BP}$ \\
\hline WP_002296469.1 & WxL domain surface protein & unknown & unknown & unknown & SRP\&virulence \\
\hline WP_002296825.1 & XRE-family-TRP & Unknown & Unknown & Unknown & SRP\&virulence \\
\hline WP_002295457.1 & XRE-family-TRP & Unknown & Unknown & Unknown & SRP\&virulence \\
\hline WP_002321678.1 & YIP1-family & Unknown & Unknown & Unknown & $\mathrm{TP}$ \\
\hline WP_002299629.1 & Zinc-ribbon_domain & Unknown & Unknown & Unknown & unknown \\
\hline WP_002286680.1 & HP & Unknown & Unknown & Unknown & unknown \\
\hline WP_002286695.1 & HP & Unknown & Unknown & Unknown & unknown \\
\hline WP_002286694.1 & HP & Unknown & Unknown & Unknown & unknown \\
\hline WP_002288892.1 & HP & Unknown & Unknown & Unknown & unknown \\
\hline WP_002311569.1 & HP & Unknown & Unknown & Unknown & unknown \\
\hline WP_002289611.1 & HP & Unknown & Unknown & Unknown & unknown \\
\hline WP_002292681.1 & HP & Unknown & Unknown & Unknown & unknown \\
\hline WP_002289266.1 & HP & Unknown & Unknown & Unknown & unknown \\
\hline WP_106018962.1 & HP & Unknown & Unknown & Unknown & unknown \\
\hline WP_059355966.1 & $\mathrm{HP}$ & Unknown & Unknown & Unknown & unknown \\
\hline WP_002295905.1 & HP & unknown & unknown & unknown & unknown \\
\hline WP_002299302.1 & HP & unknown & unknown & unknown & unknown \\
\hline WP_002288487.1 & HP & unknown & unknown & unknown & unknown \\
\hline
\end{tabular}

${ }^{*}$ BP-Binding protein; Mip-Metal ion binding protein; TP-Transport Protein; IP-Immunity Protein; SRP-Stress Response Protein; TRP-Transcription Regulator Protein; APRP- Abortive Phage Resistance Protein; PP-Predicted protein; HP-Hypothetical Protein; DUF-Domain of Unknown Function; MP-Membrane Protein; 
Table S2: Physico-chemical properties of HPs.

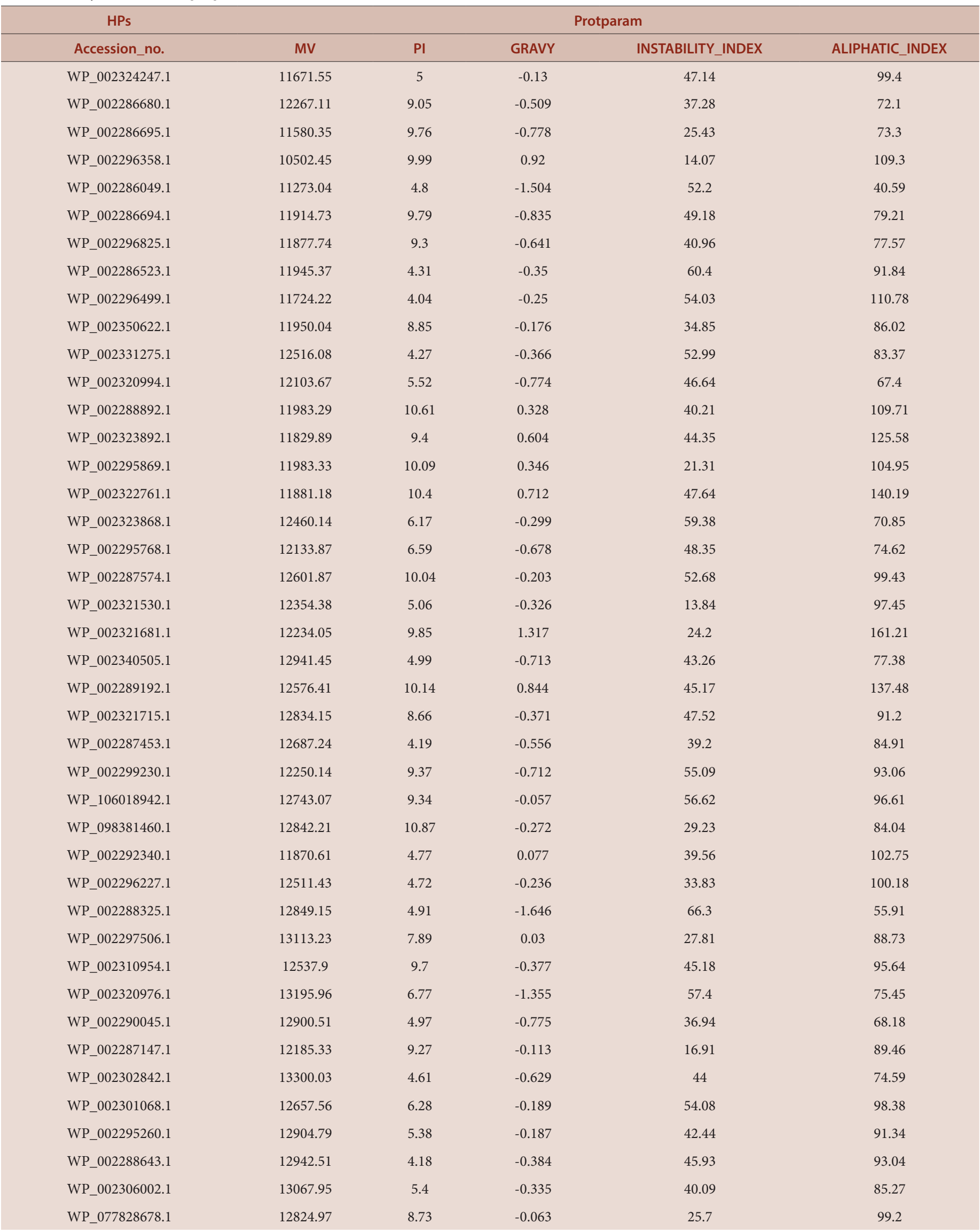




\begin{tabular}{|c|c|c|c|c|c|}
\hline WP_002341586.1 & 11926.46 & 9.45 & 1.057 & 31.14 & 128.5 \\
\hline WP_002326717.1 & 13168.26 & 9.19 & -0.55 & 47.7 & 93.27 \\
\hline WP_002286559.1 & 13375.85 & 4.43 & -0.781 & 33.41 & 90.62 \\
\hline WP_002314399.1 & 13083.46 & 4.11 & -0.56 & 32.93 & 78.41 \\
\hline WP_002321269.1 & 13156.52 & 4.21 & -0.677 & 34.15 & 71.5 \\
\hline WP_002368121.1 & 12949.99 & 6.22 & -0.236 & 21 & 100 \\
\hline WP_002287507.1 & 13448.97 & 9.84 & 0.465 & 36.13 & 115.53 \\
\hline WP_002289550.1 & 13420.87 & 10 & 0.036 & 56.76 & 97.57 \\
\hline WP_002347528.1 & 13520.19 & 5.23 & -0.69 & 49.54 & 85.57 \\
\hline WP_010706480.1 & 13604.52 & 5.64 & -0.855 & 31.15 & 74.05 \\
\hline WP_002296335.1 & 13645.39 & 4.45 & -0.38 & 51.65 & 105.95 \\
\hline WP_002303114.1 & 13599.99 & 4.71 & -0.91 & 57.45 & 79.05 \\
\hline WP_002287659.1 & 13771.03 & 8.77 & -0.343 & 30.85 & 101.62 \\
\hline WP_002321678.1 & 13583.52 & 8.97 & -0.462 & 25.44 & 75.04 \\
\hline WP_002288314.1 & 12429.36 & 7.86 & -0.223 & 22.76 & 71.95 \\
\hline WP_002296631.1 & 14051.16 & 4.74 & -0.126 & 30.14 & 103.22 \\
\hline WP_002311569.1 & 13817.38 & 9.47 & 0.114 & 21.03 & 123.05 \\
\hline WP_002341521.1 & 14076.23 & 9.61 & -0.874 & 20.86 & 85 \\
\hline WP_002293655.1 & 13794 & 5.41 & 0.097 & 53.3 & 93.36 \\
\hline WP_106018943.1 & 13964.04 & 9.07 & -0.697 & 35.07 & 79.5 \\
\hline WP_002287075.1 & 19211.99 & 6.11 & -0.417 & 20 & 79.7 \\
\hline WP_002339568.1 & 20132.07 & 5.68 & -0.675 & 26.41 & 85.35 \\
\hline WP_070828461.1 & 20099.79 & 4.61 & -0.323 & 42.08 & 92.28 \\
\hline WP_002287073.1 & 20168.14 & 8.76 & -0.383 & 26.22 & 80.94 \\
\hline WP_002285960.1 & 20340.26 & 10 & 0.254 & 26.91 & 109.36 \\
\hline WP_002303352.1 & 19747.23 & 4.94 & -0.53 & 32.28 & 81.21 \\
\hline WP_002295447.1 & 19271.88 & 4.82 & 0.664 & 42 & 117.64 \\
\hline WP_002289403.1 & 20320.52 & 5.77 & -0.21 & 49 & 98 \\
\hline WP_002289611.1 & 20929.49 & 9.65 & 0.802 & 29.12 & 136.05 \\
\hline WP_002301170.1 & 19718.54 & 9.8 & -0.236 & 33.83 & 66.48 \\
\hline WP_010729510.1 & 20323.51 & 9.3 & -0.159 & 23.45 & 91.96 \\
\hline WP_002317290.1 & 20776.11 & 8.81 & -0.167 & 46.46 & 88.89 \\
\hline WP_002292681.1 & 21071.09 & 9.5 & -0.957 & 33.81 & 81.92 \\
\hline WP_002330700.1 & 21629.62 & 5.3 & -0.299 & 48.42 & 101.64 \\
\hline WP_002295457.1 & 22261.29 & 4.92 & -0.72 & 40.73 & 89.62 \\
\hline WP_002303842.1 & 21582.19 & 9.45 & -0.34 & 49.09 & 88.66 \\
\hline WP_106018965.1 & 22565.43 & 4.93 & -0.593 & 37.41 & 95.34 \\
\hline WP_002293998.1 & 22762.5 & 10 & 0.668 & 38.93 & 123.49 \\
\hline WP_002295807.1 & 21230.78 & 4.94 & -0.42 & 30.33 & 81.54 \\
\hline WP_002350357.1 & 23520.2 & 9.42 & -0.774 & 47.99 & 89.44 \\
\hline WP_002322465.1 & 23633.24 & 4.66 & -0.523 & 45.21 & 80.25 \\
\hline WP_074400136.1 & 23389.85 & 4.6 & -0.319 & 44.41 & 100.95 \\
\hline WP_002286512.1 & 22152.03 & 4.88 & -0.286 & 20.25 & 76.73 \\
\hline WP_002286831.1 & 24129.01 & 8.95 & -0.695 & 55.69 & 73.76 \\
\hline WP_002321568.1 & 23591.14 & 5.51 & -0.067 & 52.55 & 99.76 \\
\hline
\end{tabular}




\begin{tabular}{|c|c|c|c|c|c|}
\hline WP_002289649.1 & 24551.94 & 9.13 & 0.856 & 26.69 & 132.27 \\
\hline WP_002295864.1 & 24074.62 & 5.14 & -0.297 & 40.9 & 92.71 \\
\hline WP_002293828.1 & 23488.54 & 8.81 & -0.605 & 19.82 & 76.33 \\
\hline WP_002296481.1 & 24389.66 & 4.83 & -0.354 & 32.68 & 84.33 \\
\hline WP_002294011.1 & 23320.84 & 9.84 & 0.698 & 27.09 & 108.71 \\
\hline WP_002300053.1 & 23751.97 & 4.97 & -0.107 & 32.33 & 86.38 \\
\hline WP_002289266.1 & 24247.64 & 8.71 & 0.745 & 32.22 & 108.19 \\
\hline WP_049143544.1 & 23373.27 & 5.1 & -0.25 & 30.13 & 78.95 \\
\hline WP_049143545.1 & 24112.46 & 5.12 & -0.383 & 39.42 & 99.76 \\
\hline WP_000248477.1 & 25050.43 & 5.82 & -0.722 & 33.33 & 73.07 \\
\hline WP_106018970.1 & 24286.12 & 5.01 & -0.766 & 28.4 & 77.9 \\
\hline WP_002350628.1 & 24543.51 & 9.47 & 0.851 & 18.98 & 140.19 \\
\hline WP_002298250.1 & 25517.4 & 5.46 & -0.335 & 36.85 & 95.67 \\
\hline WP_002352495.1 & 25134.91 & 6 & -0.437 & 43.07 & 98.89 \\
\hline WP_002299629.1 & 25583.38 & 4.77 & 0.059 & 44.11 & 104.17 \\
\hline WP_002303420.1 & 26048.95 & 6.11 & -0.466 & 47.39 & 92.57 \\
\hline WP_002368120.1 & 25403.11 & 6.64 & -0.471 & 33.56 & 85.02 \\
\hline WP_074400096.1 & 25975.69 & 9.47 & -0.035 & 38.2 & 115.02 \\
\hline WP_002289292.1 & 26635.24 & 6.01 & -0.868 & 48.61 & 73.8 \\
\hline WP_106018950.1 & 25437.06 & 9.02 & -0.582 & 33.54 & 86.08 \\
\hline WP_002288350.1 & 25340.24 & 8.35 & 0.733 & 19.92 & 111.52 \\
\hline WP_106018980.1 & 27529.3 & 9.6 & -1.318 & 60.82 & 64.89 \\
\hline WP_002286553.1 & 26647.8 & 9.12 & -0.373 & 34.13 & 84.25 \\
\hline WP_002303824.1 & 26838.61 & 5.28 & -0.571 & 61.04 & 80.87 \\
\hline WP_002302159.1 & 26616.63 & 5.13 & -0.298 & 74.73 & 94.59 \\
\hline WP_002346986.1 & 24732.96 & 5.3 & -0.214 & 29.12 & 72.84 \\
\hline WP_002347494.1 & 27332.83 & 7.04 & -0.954 & 51.27 & 74.45 \\
\hline WP_002296429.1 & 26100.94 & 4.78 & -0.89 & 29.37 & 86.57 \\
\hline WP_002326819.1 & 28122.47 & 4.63 & -0.83 & 52.92 & 69.09 \\
\hline WP_002289272.1 & 26863.41 & 5.76 & -0.699 & 39.15 & 82.52 \\
\hline WP_002298929.1 & 26411.57 & 4.67 & -0.387 & 43.93 & 86.48 \\
\hline WP_002325767.1 & 25427.08 & 4.88 & -0.33 & 46.29 & 74.43 \\
\hline WP_002350626.1 & 27259.08 & 4.85 & -0.168 & 28.2 & 86.34 \\
\hline WP_002326255.1 & 28149.36 & 9.18 & 0.649 & 45.65 & 117.39 \\
\hline WP_002341874.1 & 27227.76 & 9.68 & -0.63 & 45.01 & 60.08 \\
\hline WP_002289257.1 & 28753.09 & 9.5 & -1.322 & 60.41 & 52.68 \\
\hline WP_074400044.1 & 28043.14 & 4.99 & 0.226 & 26.54 & 98.35 \\
\hline WP_002286840.1 & 29618.9 & 6.07 & -0.498 & 32.8 & 83.84 \\
\hline WP_002302142.1 & 29856.17 & 5.73 & -0.255 & 34.32 & 98.12 \\
\hline WP_000185761.1 & 30671.48 & 9.27 & -0.518 & 36.33 & 78.6 \\
\hline WP_106018962.1 & 30307.74 & 6 & -0.254 & 27.1 & 96.3 \\
\hline WP_000675717.1 & 29750.71 & 5.49 & -0.425 & 34.32 & 88.8 \\
\hline WP_002304624.1 & 29063.87 & 5.23 & -0.35 & 23.13 & 88.53 \\
\hline WP_106018971.1 & 28559.42 & 5.95 & -0.1 & 45.49 & 74.64 \\
\hline WP_002326259.1 & 29222.77 & 5 & -0.502 & 45.77 & 76.81 \\
\hline
\end{tabular}




\begin{tabular}{|c|c|c|c|c|c|}
\hline WP_010730972.1 & 31131.23 & 9.32 & -0.948 & 34.93 & 65.76 \\
\hline WP_106018956.1 & 31494.9 & 5.63 & -0.818 & 33.6 & 83.66 \\
\hline WP_002287053.1 & 30804.2 & 6.9 & 0.381 & 10.91 & 110.11 \\
\hline WP_106018969.1 & 31515.02 & 6.06 & -0.796 & 29.45 & 84.74 \\
\hline WP_002340450.1 & 30755.01 & 4.89 & -0.078 & 32.47 & 91.37 \\
\hline WP_106018948.1 & 32414.29 & 7.71 & -0.402 & 36.67 & 84.05 \\
\hline WP_002321275.1 & 30819.8 & 4.58 & -0.72 & 53.8 & 68.04 \\
\hline WP_002286311.1 & 30221.97 & 4.91 & -0.388 & 11.89 & 95.36 \\
\hline WP_002342384.1 & 32072.65 & 7.69 & -0.369 & 48.14 & 94.04 \\
\hline WP_002287480.1 & 33618.76 & 8.38 & -0.49 & 41.7 & 84.04 \\
\hline WP_002317291.1 & 31094.64 & 4.65 & 0.786 & 25.44 & 118.54 \\
\hline WP_002288853.1 & 32958.77 & 4.75 & -0.441 & 37.94 & 89.69 \\
\hline WP_002286524.1 & 34677.7 & 6.03 & -0.454 & 32.94 & 86.36 \\
\hline WP_010730973.1 & 34370.76 & 9.52 & -0.442 & 28.34 & 95.09 \\
\hline WP_002302096.1 & 35382.97 & 5.79 & -0.616 & 45.66 & 75.64 \\
\hline WP_002295906.1 & 35966.8 & 4.62 & -1.084 & 55.73 & 71.34 \\
\hline WP_002323140.1 & 36657.86 & 4.97 & -0.473 & 59.82 & 90.03 \\
\hline WP_059355966.1 & 36346.01 & 8.59 & 0.182 & 38.85 & 110.87 \\
\hline WP_106018974.1 & 36499.18 & 9.65 & -0.395 & 32.76 & 91.19 \\
\hline WP_002317282.1 & 36069.64 & 9.16 & -0.704 & 45.66 & 71.18 \\
\hline WP_002295913.1 & 37036.48 & 6.98 & -0.336 & 40.78 & 91.95 \\
\hline WP_002321168.1 & 38340.79 & 9.48 & 0.696 & 29.5 & 120.06 \\
\hline WP_000455809.1 & 38991.28 & 4.79 & -0.435 & 57.6 & 88.11 \\
\hline WP_002305295.1 & 40152.82 & 5.37 & -0.285 & 47.04 & 97.55 \\
\hline WP_002347500.1 & 39053.89 & 9.18 & -0.469 & 28.25 & 66.77 \\
\hline WP_002294410.1 & 41047.52 & 5.72 & -0.14 & 36.58 & 96.93 \\
\hline WP_002295905.1 & 41404.04 & 4.47 & 5.72 & 32.17 & 86.53 \\
\hline WP_002286016.1 & 43004.68 & 5.3 & -0.549 & 35.7 & 79.75 \\
\hline WP_002288760.1 & 41783.08 & 4.98 & -0.428 & 30.84 & 85.22 \\
\hline WP_010730971.1 & 43381.45 & 8.23 & -0.609 & 33.44 & 71.02 \\
\hline WP_002295486.1 & 43317.91 & 4.7 & -0.378 & 35.29 & 82.91 \\
\hline WP_002340448.1 & 43803.37 & 7.94 & -0.303 & 34.15 & 84.26 \\
\hline WP_002335549.1 & 44729.61 & 9.14 & -0.423 & 41.24 & 93.89 \\
\hline WP_002296632.1 & 46434.53 & 9.21 & -0.545 & 43.35 & 80.03 \\
\hline WP_002287822.1 & 41389.78 & 4.79 & -0.281 & 38.11 & 82.9 \\
\hline WP_002289233.1 & 44083.91 & 5.06 & -0.35 & 34.14 & 77.28 \\
\hline WP_002299302.1 & 46378.07 & 9.52 & 0.493 & 30.9 & 117.53 \\
\hline WP_002350689.1 & 47844.06 & 9.61 & -0.693 & 31.77 & 77.21 \\
\hline WP_002287080.1 & 51417.31 & 9.42 & -0.7 & 43.17 & 79.36 \\
\hline WP_049143547.1 & 51936.19 & 9.04 & -0.468 & 49.71 & 96.81 \\
\hline WP_002344946.1 & 51576.62 & 5.07 & -0.312 & 46.05 & 90.32 \\
\hline WP_002288852.1 & 50036.18 & 5.14 & -0.456 & 28.96 & 84.52 \\
\hline WP_002350624.1 & 50189.2 & 8.04 & 0.702 & 31.91 & 123.33 \\
\hline WP_002288487.1 & 53048.91 & 6.15 & -0.516 & 40.56 & 87.71 \\
\hline WP_002296549.1 & 52491.76 & 9.53 & 0.712 & 31.9 & 128.01 \\
\hline
\end{tabular}




\begin{tabular}{|c|c|c|c|c|c|}
\hline WP_002325481.1 & 53315.37 & 9.49 & 0.621 & 22.85 & 118.12 \\
\hline WP_002287397.1 & 52056.24 & 5.04 & -0.585 & 29.15 & 73.99 \\
\hline WP_002335550.1 & 54609.63 & 9.69 & 0.825 & 25.41 & 129.41 \\
\hline WP_002341445.1 & 57736.41 & 5.2 & -0.229 & 47.65 & 104.3 \\
\hline WP_002287057.1 & 58772.17 & 7.19 & -0.234 & 46.3 & 96.87 \\
\hline WP_002287140.1 & 58290.27 & 8.7 & -0.345 & 43.83 & 93.73 \\
\hline WP_002311258.1 & 62111.65 & 6.18 & -0.275 & 43.52 & 98.4 \\
\hline WP_002289495.1 & 58704.77 & 4.79 & -0.683 & 32.68 & 86.32 \\
\hline WP_002347493.1 & 62709.11 & 7.1 & -0.383 & 39.16 & 101.25 \\
\hline WP_002350625.1 & 65492.13 & 5.68 & -0.297 & 34.1 & 93.4 \\
\hline WP_002322202.1 & 66336.21 & 9.36 & 0.343 & 38.26 & 108.83 \\
\hline WP_002289445.1 & 67721.27 & 9.4 & 0.2 & 27.89 & 107.58 \\
\hline WP_002299301.1 & 67610.94 & 9.34 & 0.536 & 31.4 & 112.77 \\
\hline WP_000163792.1 & 76746.29 & 9.28 & -0.807 & 38.31 & 65.4 \\
\hline WP_002345015.1 & 74835.58 & 4.78 & -0.403 & 31.78 & 87.39 \\
\hline WP_002296543.1 & 78530.75 & 7.09 & 0.27 & 30.98 & 104.79 \\
\hline WP_002354430.1 & 79929.47 & 4.68 & -1.081 & 56.03 & 71.42 \\
\hline WP_002287056.1 & 76493.94 & 5.96 & -0.597 & 46.2 & 77.99 \\
\hline WP_002286495.1 & 78321.65 & 5.11 & -0.399 & 25.44 & 80.83 \\
\hline WP_002296832.1 & 82358.03 & 5.69 & -0.458 & 43.25 & 95.72 \\
\hline WP_002325891.1 & 76931.22 & 4.81 & -0.627 & 32.93 & 65.06 \\
\hline WP_002296595.1 & 84901.12 & 5.01 & -0.351 & 18.09 & 83.42 \\
\hline WP_002296469.1 & 89435.15 & 5.3 & -0.223 & 26.63 & 83.37 \\
\hline WP_101706209.1 & 92778.07 & 6.23 & -0.437 & 29.93 & 88.16 \\
\hline WP_002340339.1 & 91739.41 & 4.66 & -0.388 & 28.48 & 76.77 \\
\hline WP_002340550.1 & 99264.3 & 9.04 & -0.46 & 28.76 & 79.67 \\
\hline WP_002286213.1 & 107021 & 5.74 & -0.755 & 52.34 & 84.55 \\
\hline
\end{tabular}

Table S3: Subcellular localization and virulence prediction of HPs.

\begin{tabular}{|c|c|c|c|c|}
\hline $\begin{array}{c}\text { HPs } \\
\text { Accession_no. }\end{array}$ & \multicolumn{2}{|c|}{ Subcellular_localization } & \multicolumn{2}{|c|}{ VF_prediction } \\
\hline WP_002324247.1 & Cytoplasmic & Extracell & $\mathrm{MM}$ & Virulent \\
\hline WP_002286695.1 & Cytoplasmic & CM/Cytoplasm & $\mathrm{CP}$ & Virulent \\
\hline WP_002296358.1 & IM & $\mathrm{CM}$ & MM & Non-virulent \\
\hline WP_002286694.1 & Cytoplasmic & Cytoplasm/Extracell & MM & Virulent \\
\hline WP_002296825.1 & Cytoplasmic & Extracell & $\mathrm{CP}$ & Non-virulent \\
\hline WP_002286523.1 & Cytoplasmic & Extracell & $\mathrm{MM}$ & Virulent \\
\hline WP_002296499.1 & Cytoplasmic & Cytoplasm & $\mathrm{CP}$ & Virulent \\
\hline WP_002288892.1 & Cytoplasmic & $\mathrm{CM}$ & $\mathrm{CP}$ & Virulent \\
\hline WP_002323892.1 & IM & $\mathrm{CM}$ & $\mathrm{CP}$ & Virulent \\
\hline
\end{tabular}




\begin{tabular}{|c|c|c|c|c|}
\hline WP_002295869.1 & Periplasmic & $\mathrm{CM}$ & $\mathrm{CP}$ & Virulent \\
\hline WP_002322761.1 & IM & $\mathrm{CM}$ & $\mathrm{MM}$ & Virulent \\
\hline WP_002323868.1 & Periplasmic & $\mathrm{CM}$ & $\mathrm{CP}$ & Virulent \\
\hline WP_002295768.1 & Cytoplasmic & CM/Extracell & MM & Non-Virulent \\
\hline WP_002287574.1 & Cytoplasmic & $\mathrm{CM}$ & $\mathrm{CP}$ & Virulent \\
\hline WP_002321530.1 & Cytoplasmic & Extracell & $\mathrm{CP}$ & Non-Virulent \\
\hline WP_002321681.1 & IM & $\mathrm{CM}$ & MM & Virulent \\
\hline WP_002340505.1 & Cytoplasmic(PM1500) & $\mathrm{CM}$ & $\mathrm{CP}$ & Virulent \\
\hline WP_002289192.1 & IM & $\mathrm{CM}$ & MM & Virulent \\
\hline WP_002321715.1 & Cytoplasmic & CM/Extracell & MM & Virulent \\
\hline WP_002287453.1 & Cytoplasmic & Cytoplasm & $\mathrm{CP}$ & Virulent \\
\hline WP_002299230.1 & Cytoplasmic & Extracell & IS & Virulent \\
\hline WP_106018942.1 & Cytoplasmic & $\mathrm{CM}$ & MM & Virulent \\
\hline WP_098381460.1 & Periplasmic & CM/Extracell & $\mathrm{MM}$ & Virulent \\
\hline WP_002292340.1 & Cytoplasmic(yaaQ) & Cytoplasm & $\mathrm{CP}$ & Virulent \\
\hline WP_002296227.1 & Cytoplasmic & Extracell & IS & Virulent \\
\hline WP_002288325.1 & Cytoplasmic & Cytoplasm & $\mathrm{CP}$ & Virulent \\
\hline WP_002297506.1 & IM & $\mathrm{CM}$ & MM & Virulent \\
\hline WP_002310954.1 & Cytoplasmic & CM/Cytoplasm & MM & Virulent \\
\hline WP_002320976.1 & Cytoplasmic & CM/Cytoplasm & MM & Virulent \\
\hline WP_002290045.1 & Cytoplasmic(ypjD) & Cytoplasm & $\mathrm{CP}$ & Virulent \\
\hline WP_002287147.1 & Periplasmic & Extracell & $\mathrm{CP}$ & Virulent \\
\hline WP_002302842.1 & Cytoplasmic & CM/Cytoplasm & $\mathrm{CP}$ & Virulent \\
\hline WP_002301068.1 & Cytoplasmic/OM & $\mathrm{CM}$ & $\mathrm{CP}$ & Virulent \\
\hline WP_002295260.1 & Cytoplasmic & $\mathrm{CM}$ & VF & Virulent \\
\hline WP_002288643.1 & Cytoplasmic(ydfE) & Extracell & $\mathrm{CP}$ & Virulent \\
\hline WP_002306002.1 & Cytoplasmic(insF) & $\mathrm{CM}$ & $\mathrm{CP}$ & Virulent \\
\hline WP_077828678.1 & IM & CM/Cytoplasm & MM & Non-Virulent \\
\hline WP_002341586.1 & Cytoplasmic & $\mathrm{CM}$ & MM & Virulent \\
\hline WP_002326717.1 & Cytoplasmic & Extracell & $\mathrm{CP}$ & Virulent \\
\hline WP_002286559.1 & Cytoplasmic(EF_A0048) & Extracell & MM & Virulent \\
\hline WP_002314399.1 & Cytoplasmic(EF_A0048) & $\mathrm{CM} / \mathrm{CW}$ & $\mathrm{CP}$ & Virulent \\
\hline WP_002321269.1 & Cytoplasmic & CM/Cytoplasm & $\mathrm{CP}$ & Virulent \\
\hline WP_002368121.1 & IM & Extracell & VF & Virulent \\
\hline WP_002287507.1 & Cytoplasmic & $\mathrm{CM}$ & MM & Virulent \\
\hline WP_002289550.1 & Cytoplasmic & $\mathrm{CM}$ & MM & Non-Virulent \\
\hline WP_002347528.1 & Cytoplasmic & Extracell & MM & Virulent \\
\hline WP_010706480.1 & Cytoplasmic & Extracell & $\mathrm{CP}$ & Virulent \\
\hline WP_002296335.1 & Cytoplasmic & Cytoplasm & IS & Non-Virulent \\
\hline WP_002303114.1 & Cytoplasmic(NGR_a03130) & Cytoplasm/Extracell & MM & Virulent \\
\hline WP_002287659.1 & Periplasmic & Cytoplasm & VF & Non-Virulent \\
\hline WP_002321678.1 & Cytoplasmic & $\mathrm{CM}$ & $\mathrm{CP}$ & Non-Virulent \\
\hline WP_002288314.1 & Cytoplasmic & Extracell & $\mathrm{CP}$ & Virulent \\
\hline WP_002296631.1 & Cytoplasmic & $\mathrm{CM}$ & MM & Virulent \\
\hline WP_002311569.1 & Cytoplasmic(ps201) & $\mathrm{CM}$ & MM & Virulent \\
\hline
\end{tabular}




\begin{tabular}{|c|c|c|c|c|}
\hline WP_002341521.1 & Cytoplasmic & $\mathrm{CM} /$ Extracell & $\mathrm{CP}$ & Virulent \\
\hline WP_002293655.1 & Cytoplasmic & $\mathrm{CM}$ & $\mathrm{CP}$ & Virulent \\
\hline WP_106018943.1 & Cytoplasmic & CM/Extracell & $\mathrm{CP}$ & Non-Virulent \\
\hline WP_002287075.1 & Cytoplasmic & Extracell & MM & Non-virulent \\
\hline WP_002339568.1 & Cytoplasmic & Extracell & $\mathrm{CP}$ & Virulent \\
\hline WP_070828461.1 & Cytoplasmic(yxjI) & $\mathrm{CM}$ & $\mathrm{CP}$ & Virulent \\
\hline WP_002287073.1 & $\mathrm{IM}$ & $\mathrm{CM}$ & MM & Virulent \\
\hline WP_002285960.1 & Cytoplasmic(yddH) & $\mathrm{CM}$ & $\mathrm{CP}$ & Virulent \\
\hline WP_002303352.1 & Cytoplasmic(yuaF) & Extracell & IS & Non-Virulent \\
\hline WP_002295447.1 & Cytoplasmic & $\mathrm{CM}$ & MM & Virulent \\
\hline WP_002289403.1 & $\mathrm{IM}$ & Extracell & $\mathrm{CP}$ & Virulent \\
\hline WP_002289611.1 & Extracellular & $\mathrm{CM}$ & $\mathrm{CP}$ & Virulent \\
\hline WP_002301170.1 & $\mathrm{OM}$ & Extracell & MM & Virulent \\
\hline WP_010729510.1 & Cytoplasmic(munIM) & Extracell & MM & Non-virulent \\
\hline WP_002317290.1 & Cytoplasmic & Cytoplasm & IS & Virulent \\
\hline WP_002292681.1 & Cytoplasmic & Cytoplasm/Extracell & MM & Virulent \\
\hline WP_002330700.1 & Cytoplasmic & $\mathrm{CM}$ & VF & Virulent \\
\hline WP_002295457.1 & Cytoplasmic & Extracell & $\mathrm{CP}$ & Virulent \\
\hline WP_002303842.1 & Cytoplasmic & CM/Cytoplasm & $\mathrm{CP}$ & Virulent \\
\hline WP_106018965.1 & IM & $\mathrm{CM}$ & $\mathrm{CP}$ & Non-virulent \\
\hline WP_002293998.1 & Cytoplasmic & $\mathrm{CM}$ & MM & Non-virulent \\
\hline WP_002295807.1 & Cytoplasmic(pXO2-10) & Extracell & $\mathrm{CP}$ & Virulent \\
\hline WP_002350357.1 & Cytoplasmic & $\mathrm{CM} /$ Extracell & MM & Virulent \\
\hline WP_002322465.1 & Cytoplasmic & $\mathrm{CM}$ & MM & Virulent \\
\hline WP_074400136.1 & Cytoplasmic & $\mathrm{CM} /$ Extracell & $\mathrm{CP}$ & Virulent \\
\hline WP_002286512.1 & Cytoplasmic & Extracell & $\mathrm{CP}$ & Non-virulent \\
\hline WP_002286831.1 & Cytoplasmic & Cytoplasm & $\mathrm{CP}$ & Virulent \\
\hline WP_002321568.1 & IM & Extracell & MM & Virulent \\
\hline WP_002289649.1 & Cytoplasmic & $\mathrm{CM}$ & $\mathrm{CP}$ & Non-virulent \\
\hline WP_002295864.1 & Extracellular & CM/Cytoplasm & $\mathrm{CP}$ & Virulent \\
\hline WP_002293828.1 & Cytoplasmic & Extracell & $\mathrm{CP}$ & Virulent \\
\hline WP_002296481.1 & $\operatorname{IM}(\operatorname{niaX})$ & $\mathrm{CM}$ & $\mathrm{CP}$ & Non-virulent \\
\hline WP_002294011.1 & Cytoplasmic(yisX) & $\mathrm{CM}$ & MM & Virulent \\
\hline WP_002300053.1 & IM & CM/Cytoplasm & $\mathrm{CP}$ & Virulent \\
\hline WP_002289266.1 & Extracellular & $\mathrm{CM}$ & $\mathrm{CP}$ & Virulent \\
\hline WP_049143544.1 & Cytoplasmic & Extracell & $\mathrm{CP}$ & Virulent \\
\hline WP_049143545.1 & $\mathrm{OM}$ & Extracell & $\mathrm{CP}$ & Virulent \\
\hline WP_000248477.1 & $\mathrm{OM}$ & $\mathrm{CM}$ & $\mathrm{CP}$ & Virulent \\
\hline WP_106018970.1 & IM & Extracell & $\mathrm{CP}$ & Virulent \\
\hline WP_002350628.1 & Cytoplasmic & $\mathrm{CM}$ & $\mathrm{CP}$ & Virulent \\
\hline WP_002298250.1 & Cytoplasmic(xpaC) & CM/Cytoplasm & $\mathrm{CP}$ & Virulent \\
\hline WP_002352495.1 & IM & CM/Cytoplasm. & $\mathrm{CP}$ & Virulent \\
\hline WP_002299629.1 & Cytoplasmic & $\mathrm{CM}$ & MM & Virulent \\
\hline WP_002303420.1 & Cytoplasmic & $\mathrm{CM}$ & MM & Virulent \\
\hline WP_002368120.1 & Cytoplasmic & CM/Extracell & $\mathrm{CP}$ & Virulent \\
\hline
\end{tabular}




\begin{tabular}{|c|c|c|c|c|}
\hline WP_074400096.1 & Cytoplasmic(HI_0552) & $\mathrm{CM}$ & $\mathrm{CP}$ & Virulent \\
\hline WP_002289292.1 & Cytoplasmic(tnp) & CM/Cytoplasm & $\mathrm{CP}$ & Virulent \\
\hline WP_106018950.1 & $\mathrm{IM}$ & CM/Cytoplasm & $\mathrm{CP}$ & Non-Virulent \\
\hline WP_002288350.1 & Cytoplasmic & $\mathrm{CM}$ & $\mathrm{MM}$ & Virulent \\
\hline WP_106018980.1 & Cytoplasmic & Cytoplasm & IS & Virulent \\
\hline WP_002286553.1 & Cytoplasmic & $\mathrm{CM} /$ Extracell & $\mathrm{MM}$ & Non-Virulent \\
\hline WP_002303824.1 & Cytoplasmic & Cytoplasm & $\mathrm{CP}$ & Virulent \\
\hline WP_002302159.1 & Extracellular & Cytoplasm & IS & Non-Virulent \\
\hline WP_002346986.1 & Cytoplasmic & Extracell & $\mathrm{CP}$ & Non-Virulent \\
\hline WP_002347494.1 & Cytoplasmic & Extracell & $\mathrm{MM}$ & Virulent \\
\hline WP_002296429.1 & Cytoplasmic & $\mathrm{CM}$ & $\mathrm{CP}$ & Virulent \\
\hline WP_002326819.1 & Cytoplasmic & $\mathrm{CM}$ & $\mathrm{CP}$ & Virulent \\
\hline WP_002289272.1 & Cytoplasmic & Extracell & $\mathrm{CP}$ & Non-Virulent \\
\hline WP_002298929.1 & Extracellular(ydeJ) & Cytoplasm & IS & Virulent \\
\hline WP_002325767.1 & Cytoplasmic & CM/Extracell & $\mathrm{MM}$ & Non-Virulent \\
\hline WP_002350626.1 & IM & Cytoplasm & $\mathrm{CP}$ & Virulent \\
\hline WP_002326255.1 & $\mathrm{OM}$ & $\mathrm{CM}$ & $\mathrm{CP}$ & Virulent \\
\hline WP_002341874.1 & $\mathrm{OM}$ & Extracell & $\mathrm{MM}$ & Virulent \\
\hline WP_002289257.1 & IM & Extracell & $\mathrm{CP}$ & Non-virulent \\
\hline WP_074400044.1 & Cytoplasmic & $\mathrm{CM}$ & $\mathrm{MM}$ & Virulent \\
\hline WP_002286840.1 & $\mathrm{OM}$ & $\mathrm{CM}$ & $\mathrm{CP}$ & Virulent \\
\hline WP_002302142.1 & Cytoplasmic & $\mathrm{CM}$ & $\mathrm{MM}$ & Virulent \\
\hline WP_000185761.1 & Cytoplasmic & $\mathrm{CM}$ & $\mathrm{CP}$ & Virulent \\
\hline WP_106018962.1 & Cytoplasmic & $\mathrm{CM}$ & $\mathrm{CP}$ & Virulent \\
\hline WP_000675717.1 & Periplasmic & Extracell & $\mathrm{CP}$ & Virulent \\
\hline WP_002304624.1 & $\mathrm{OM}$ & Extracell & $\mathrm{CP}$ & Virulent \\
\hline WP_106018971.1 & $\mathrm{OM}$ & Extracell & MM & Virulent \\
\hline WP_002326259.1 & Cytoplasmic & CM/Extracell & $\mathrm{CP}$ & Virulent \\
\hline WP_010730972.1 & Cytoplasmic(pXO2-05) & Extracell & $\mathrm{CP}$ & Virulent \\
\hline WP_106018956.1 & IM(TM_0562.1) & CM/Cytoplasm & MM & Virulent \\
\hline WP_002287053.1 & Cytoplasmic(pXO2-05) & $\mathrm{CM}$ & MM & Virulent \\
\hline WP_106018969.1 & Cytoplasmic & Cytoplasm/Extracell & $\mathrm{CP}$ & Virulent \\
\hline WP_002340450.1 & Cytoplasmic & CM/Cytoplasm & MM & Virulent \\
\hline WP_106018948.1 & Extracellular & $\mathrm{CM}$ & $\mathrm{CP}$ & Virulent \\
\hline WP_002321275.1 & Extracellular & Extracell & $\mathrm{MM}$ & Virulent \\
\hline WP_002286311.1 & Cytoplasmic(HI_0787) & Extracell & $\mathrm{CP}$ & Virulent \\
\hline WP_002342384.1 & Cytoplasmic & Extracell & MM & Virulent \\
\hline WP_002287480.1 & IM & $\mathrm{CM}$ & $\mathrm{CP}$ & Non-Virulent \\
\hline WP_002317291.1 & $\mathrm{OM}(\mathrm{yycI})$ & $\mathrm{CM}$ & $\mathrm{CP}$ & Virulent \\
\hline WP_002288853.1 & Cytoplasmic & Extracell & VF & Virulent \\
\hline WP_002286524.1 & Cytoplasmic & $\mathrm{CM}$ & $\mathrm{CP}$ & Virulent \\
\hline WP_010730973.1 & Cytoplasmic(rfaS) & $\mathrm{CM}$ & $\mathrm{CP}$ & Non-Virulent \\
\hline WP_002302096.1 & Cytoplasmic & $\mathrm{CM}$ & $\mathrm{CP}$ & Virulent \\
\hline WP_002295906.1 & Cytoplasmic & Cytoplasm & IS & Virulent \\
\hline WP_002323140.1 & Membrane & CIM/Cytoplasm & $\mathrm{CP}$ & Virulent \\
\hline
\end{tabular}




\begin{tabular}{|c|c|c|c|c|}
\hline WP_059355966.1 & Cytoplasmic & CM. & VF & Virulent \\
\hline WP_106018974.1 & Cytoplasmic & $\mathrm{CM} /$ Extracell & MM & Non-Virulent \\
\hline WP_002317282.1 & Cytoplasmic & CM/Extracell & VF & Non-Virulent \\
\hline WP_002295913.1 & Membrane & $\mathrm{CM}$ & MM & Virulent \\
\hline WP_002321168.1 & Cytoplasmic & $\mathrm{CM}$ & $\mathrm{CP}$ & Virulent \\
\hline WP_000455809.1 & Cytoplasmic(ypbB) & $\mathrm{CM}$ & $\mathrm{CP}$ & Virulent \\
\hline WP_002305295.1 & Extracellular & $\mathrm{CM}$ & MM & Virulent \\
\hline WP_002347500.1 & Cytoplasmic(aroB) & Extracell & MM & Non-Virulent \\
\hline WP_002294410.1 & Cytoplasmic & $\mathrm{CM}$ & $\mathrm{CP}$ & Virulent \\
\hline WP_002295905.1 & Cytoplasmic(yteR,yesR) & Extracell & $\mathrm{CP}$ & Non-virulent \\
\hline WP_002286016.1 & Cytoplasmic & Cytoplasm & MM & Non-virulent \\
\hline WP_002288760.1 & Cytoplasmic & Extracell & MM & Virulent \\
\hline WP_010730971.1 & Cytoplasmic(ylbC) & CM/Extracell & MM & Virulent \\
\hline WP_002295486.1 & Extracellular & Extracell & MM & Virulent \\
\hline WP_002340448.1 & CytoplasmictarF & $\mathrm{CM}$ & $\mathrm{CP}$ & Virulent \\
\hline WP_002335549.1 & Cytoplasmic & $\mathrm{CM}$ & IS & Virulent \\
\hline WP_002296632.1 & Cytoplasmic(ybbR) & $\mathrm{CM}$ & IS & Virulent \\
\hline WP_002287822.1 & Cytoplasmic(ydjG) & $\mathrm{CM}$ & $\mathrm{CP}$ & Non-Virulent \\
\hline WP_002289233.1 & Membrane & CM/Extracell & $\mathrm{MM}$ & Virulent \\
\hline WP_002299302.1 & Cytoplasmic & $\mathrm{CM}$ & $\mathrm{CP}$ & Virulent \\
\hline WP_002350689.1 & Cytoplasmic & Extracell & IS & Virulent \\
\hline WP_002287080.1 & Cytoplasmic & CM/Cytoplasm & $\mathrm{CP}$ & Non-Virulent \\
\hline WP_049143547.1 & Cytoplasmic & $\mathrm{CM}$ & IS & Virulent \\
\hline WP_002344946.1 & Extracellular & $\mathrm{CM}$ & $\mathrm{CP}$ & Virulent \\
\hline WP_002288852.1 & Membrane & CM/Extracell & $\mathrm{CP}$ & Virulent \\
\hline WP_002350624.1 & Cytoplasmic & $\mathrm{CM}$ & MM & Virulent \\
\hline WP_002288487.1 & Membrane & $\mathrm{CM}$ & IS & Non-Virulent \\
\hline WP_002296549.1 & Membrane & $\mathrm{CM}$ & MM & Non-virulent \\
\hline WP_002325481.1 & Extracellular & $\mathrm{CM}$ & MM & Virulent \\
\hline WP_002287397.1 & Membrane(rfbX) & Extracell & MM & Non-virulent \\
\hline WP_002335550.1 & Cytoplasmic & $\mathrm{CM}$ & MM & Virulent \\
\hline WP_002341445.1 & Cytoplasmic & $\mathrm{CM}$ & $\mathrm{CP}$ & Virulent \\
\hline WP_002287057.1 & Cytoplasmic & $\mathrm{CM}$ & MM & Virulent \\
\hline WP_002287140.1 & Cytoplasmic(SP_1800) & $\mathrm{CM}$ & $\mathrm{CP}$ & Virulent \\
\hline WP_002311258.1 & Cytoplasmic(yvlB) & $\mathrm{CM}$ & $\mathrm{CP}$ & Virulent \\
\hline WP_002289495.1 & Cytoplasmic & $\mathrm{CM}$ & VF & Virulent \\
\hline WP_002347493.1 & Cytoplasmic & Extracell & $\mathrm{CP}$ & Virulent \\
\hline WP_002350625.1 & Membrane & $\mathrm{CM}$ & $\mathrm{CP}$ & Non-Virulent \\
\hline WP_002322202.1 & Membrane & $\mathrm{CM}$ & $\mathrm{CP}$ & Non-Virulent \\
\hline WP_002289445.1 & Membrane & $\mathrm{CM}$ & $\mathrm{CP}$ & Non-Virulent \\
\hline WP_002299301.1 & Cytoplasmic & $\mathrm{CM}$ & IS & Virulent \\
\hline WP_000163792.1 & Extracellular(cry22Aa) & $\mathrm{CM} /$ Extracell & IS & Virulent \\
\hline WP_002345015.1 & Membrane & Extracell & $\mathrm{CP}$ & Non-Virulent \\
\hline WP_002296543.1 & Cytoplasmic & $\mathrm{CM}$ & $\mathrm{CP}$ & Virulent \\
\hline WP_002354430.1 & Extracellular & $\mathrm{CM}$ & $\mathrm{CP}$ & Virulent \\
\hline
\end{tabular}


Pownraj, et al.: Functional Annotation of Hypothetical Proteins from E. faecium Strain 13-022

\begin{tabular}{|c|c|c|c|c|}
\hline WP_002287056.1 & Extracellular & Extracell & MM & Virulent \\
\hline WP_002286495.1 & Cytoplasmic(helD) & CM/Extracell & VF & Non-virulent \\
\hline WP_002296832.1 & Extracellular(flgJ) & Extracell & MM & Virulent \\
\hline WP_002325891.1 & Extracellular & Extracell & $\mathrm{CP}$ & Virulent \\
\hline WP_002296595.1 & Extracellular & Extracell & VF & Virulent \\
\hline WP_002296469.1 & Membrane(pXO2-14) & CM/Extracell & $\mathrm{CP}$ & Virulent \\
\hline WP_101706209.1 & Extracellular & CW/Extracell & VF & Virulent \\
\hline WP_002340339.1 & Membrane(pXO2-14) & Extracell & VF & Virulent \\
\hline WP_002340550.1 & Cytoplasmic(yhaN) & Extracell & VF & Virulent \\
\hline WP_002286213.1 & Cytoplasmic & CIM & VF & Virulent \\
\hline
\end{tabular}

"CyM-Cytoplasmic membrane; CIM-Cell inner membrane; VF-Virulence Factors; CW-Cell Wall; CM-Cell Membrane; CP-Cellular Process; IS-information and Storage; MM- Metabolism Molecule;

${ }^{s}$ CELLO2GO-GO represented within the brackets () 